\title{
Efficient Rhodium-Catalysed Multicomponent Reaction for the Synthesis of Novel Propargylamines
}

Laura Rubio-Pérez,[a] Manuel Iglesias, ${ }^{*}[a]$ Julen Munárriz,[b] Victor Polo,[b] Jesús J. PérezTorrente[a] and Luis A. Oro*[a,c]

Abstract: $[\mathrm{Rh}(\mu-\mathrm{Cl})(\mathrm{H}) 2(\operatorname{IPr})] 2$ was found to be an efficient catalyst for the synthesis of novel propargylamines by a one-pot three component reaction between primary arylamines, aliphatic aldehydes and triisopropylsilylacetylene. This methodology offers an efficient synthetic pathway for the preparation of secondary propargylamines derived from aliphatic aldehydes. The reactivity of $[\mathrm{Rh}(\mu-\mathrm{Cl})(\mathrm{H}) 2(\mathrm{IPr})] 2$ with amines and aldehydes was studied, leading to the identification of complexes $[\mathrm{RhCl}(\mathrm{CO}) \operatorname{IPr}(\mathrm{MesNH} 2)]$ and $[\mathrm{RhCl}(\mathrm{CO}) 2 \mathrm{IPr}]$. The latter shows very low catalytic activity while the former brings about reaction rates similar to those obtained with $[\mathrm{Rh}(\mu-\mathrm{Cl})(\mathrm{H}) 2(\mathrm{IPr})] 2$. Besides, complex $[\mathrm{RhCl}(\mathrm{CO}) \operatorname{IPr}(\mathrm{MesNH} 2)]$ reacts with an excess of amine and aldehyde to give $[\mathrm{RhCl}(\mathrm{CO}) \operatorname{IPr}(\mathrm{MesN}=\mathrm{CHCH} 2 \mathrm{CH}(\mathrm{CH} 3) 2)]$, which has been postulated as the active species. A mechanism that clarifies the scarcely studied catalytic cycle of A3-coupling reactions is proposed based on reactivity studies and DFT calculations.

Introduction

In recent times many efforts have been devoted to the development of multicomponent reactions (MCRs). MCRs are one-pot reactions where the final product incorporates most of the atoms of at least three different reactants.[1] This strategy offers several advantages compared to multi-step synthesis: (i) atom economy, as all the starting materials need to be incorporated into the product with minimum atom waste; (ii) time- and solvent-efficiency due to the reduction of synthetic steps; (iii) formation of various bonds in a single synthetic step (high bond-forming efficiency).

In particular, several examples of MCRs have been described for the preparation of propargylamines starting from aldehydes, amines and alkynes, commonly called A3-coupling reaction.[2] These reports have mainly focused on secondary amines (Scheme 1a),[3] while primary amines are more challenging substrates (Scheme 1b-d).[4] For example, the catalyst based on silver oxide nanoparticles reported by Sun and co-workers is efficient for a variety of secondary amines, but no reaction was observed for any of the primary amines tested therein.[3h] Moreover, examples of this type of reaction are in most cases limited to cyclic secondary amines.

In particular, studies that deal with the reaction of primary aromatic amines and aliphatic aldehydes by means of a three-component coupling are scarce, especially on the lookout for methodologies that offer a wide substrate scope (Scheme 1d). Wei and co-workers reported one example,[4b] namely the coupling of pivalaldehyde with aniline and phenylacetylene, which leads to the corresponding propargylamine in a $64 \%$ yield with a $\mathrm{RuCl} 3 / \mathrm{CuBr}$ system as catalyst. A ZnMe2 mediated alkynylation of imines (three-component reaction from oanisidine, various aliphatic aldehydes and phenylacetylene) was published by Bolm and co- 
workers. This methodology, however, requires over-stoichiometric amounts of ZnMe2 and reaction times that span from 48 to $96 \mathrm{~h}$.

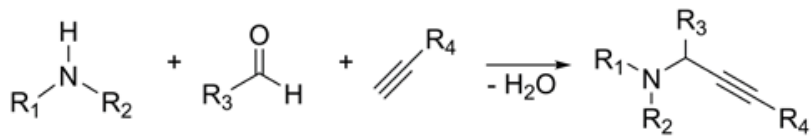

a) $R_{1}=$ Alk; $R_{2}=$ Alk; $R_{3}=$ Alk or Ar; $R_{4}=$ Any $^{2}$

b) $R_{1}=$ Alk; $R_{2}=H ; R_{3}=A r ; R_{4}=A n y^{3 c}$

c) $R_{1}=$ Alk; $R_{2}=H ; R_{3}=$ Alk ( $(\mathrm{Pr}) ; R_{4}=$ Any $^{3 a}$

d) $R_{1}=A r ; R_{2}=H ; R_{3}=A l k ; R_{4}=A n y^{3 b, c}$

e) $R_{1}=A r ; R_{2}=H ; R_{3}=A r ; R_{4}=A n y^{3 b, d}$

Scheme 1. Summary of reported examples of multicomponent reactions for the hydroalkynylation of imines from amines, aldehydes and terminal alkynes.

The importance of new efficient routes to secondary propargylamines is well exemplified by the great amount of drugs based on this organic scaffold, e.g., MAO type B inhibitors and muscarinic agonists/antagonists are commonly used in therapies for the early treatment of Parkinson's disease.[5] Moreover, propargylamines are versatile building blocks for the preparation of biologically active molecules and materials by "click chemistry" reactions. [6] Hence, mechanistic investigations that permit a better understanding of the A3-coupling reaction and the hydroalkynylation of imines may facilitate the development of more active and selective catalysts for the preparation of propargylamines. The few catalytic cycles described in the literature often propose the formation of alkynyl complexes followed by migratory insertion of the imine or iminium cation into the $\mathrm{Rh}-\mathrm{C}$ bond to finally afford the corresponding propargylamine. The information that can be obtained from these reports, however, is limited from a mechanistic viewpoint.[3e-f,4b-c] In this regard, we have recently postulated a mechanism for the hydroalkynylation of imines catalysed by a bimetallic $\operatorname{Ir}($ II) complex.[7]

$\mathrm{N}$-heterocyclic carbene (NHC) ligands have extensively proved excellent ancillary ligands for homogeneous transition metal catalysts.[8] The high stability of NHC complexes and their ability to promote oxidative addition reactions under mild conditions makes them exceptional candidates for $\mathrm{C}-\mathrm{H}$ bond functionalization reactions.[9] In particular, NHC-complex $[\mathrm{Rh}(\mu-$ $\mathrm{Cl})(\mathrm{H}) 2(\mathrm{IPr})] 2[10] \quad(\mathrm{IPr}=1,3$-bis-(2,6-diisopropylphenyl)imidazol-2-ylidene) has proven an efficient catalyst for processes that require a $\mathrm{C}-\mathrm{H}$ bond activation step, even improving the performance of its parent complex $[\mathrm{Rh}(\mu-\mathrm{Cl})(\mathrm{COE})(\operatorname{IPr})] 2(1),[11]$ which has shown good activities for the functionalization of alkynes and olefins.[12]

In this work we report the preparation of a variety of new propargylamines by a $\mathrm{Rh}$ (III) catalysed one-pot multicomponent reaction. This methodology converts a wide range of aromatic amines and aliphatic aldehydes into propargylamines in excellent yields under relatively mild reaction conditions employing $[\mathrm{Rh}(\mu-\mathrm{Cl})(\mathrm{H}) 2(\mathrm{IPr})] 2$ as precatalyst. Moreover, a study that aims at shedding light on the nature of the active species, as well as the catalytic cycle that operates in this reaction, is presented here.

Results and Discussion 
The dearth of examples of hydroalkynylation of imines derived from aromatic primary amines and aliphatic aldehydes prompted us to engage their synthesis using $[\operatorname{Rh}(\square-\mathrm{Cl})(\mathrm{H}) 2(\operatorname{IPr})] 2(2)$ as catalyst. Efforts to isolate the imines required for this reaction met with limited success due to the tendency of these compounds to hydrolyse, which accounts for the lack of synthetic methods for the preparation of their related propargylamines. Therefore, in order to circumvent this problem, the corresponding three-component reactions (A3-coupling) were investigated.

At the outset of this study, the reaction of isovaleraldehyde $(0.265 \mathrm{mmol})$ with a range of aniline derivatives $(0.265 \mathrm{mmol})$ and triisopropylsilylacetylene $(0.265 \mathrm{mmol})$ was tested in order to assess the tolerance of this methodology to various functional groups (Scheme 2).

The reactions were carried out in NMR tubes using benzene-d6 as solvent, $5 \mathrm{~mol} \%$ of catalyst (2) and kept at $80{ }^{\circ} \mathrm{C}$ for periods that spanned from 7 to $24 \mathrm{~h}$ to afford the corresponding propargylamines $(6 \mathrm{a}-6 \mathrm{~g})$ in good to excellent yields (74-97\%). As a general trend, reactions worked well with mono-, di- and trisubstituted anilines containing either electron-donating or withdrawing groups. The presence of halogen substituents such as $-\mathrm{F}$ at the ortho position of the aniline has a moderate deactivating effect as the yield for $6 \mathrm{~g}$ drops to $74 \%$. In the case of $6 a$ with an ortho-OMe group, a comparable yield was obtained (91\%). Gratifyingly, the increase of steric hindrance at the aniline, e.g., 2,6-dimethylaniline, 2,4,6-trimethylaniline, 2,6diisopropylaniline and 2,4,6-tert-butylaniline did not affect the outcome of the reaction, providing the corresponding propargylamines in yields up to $97 \%$.

Noteworthy, the use of less encumbered silylacetylenes such as triethylsilylacetylene or trimethylsilylacetylene led to worse conversions due to the formation of several by-products, which include those originated from alkyne dimerisation, trimerisation and polymerisation.

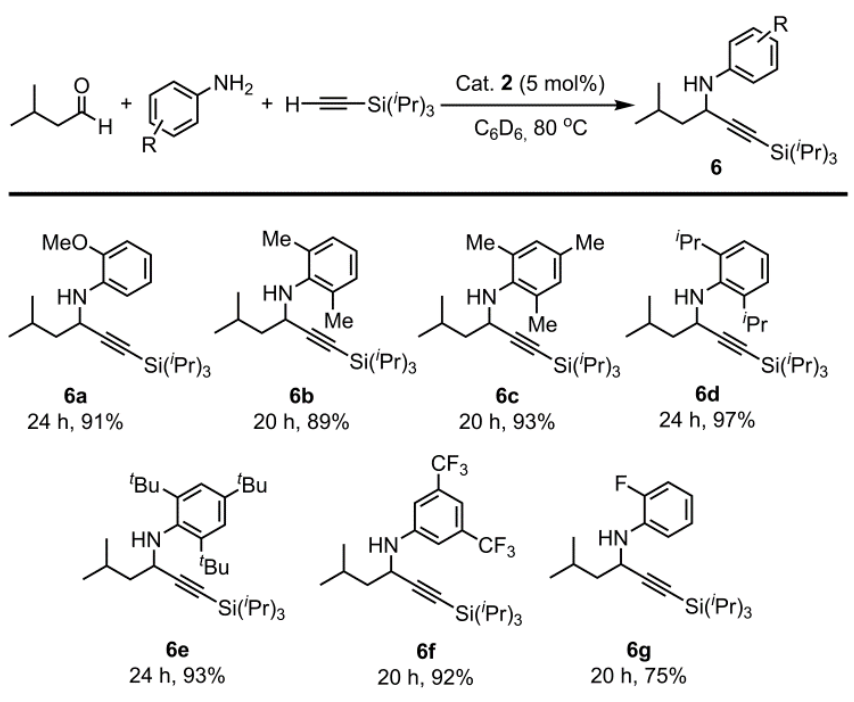

Scheme 2. A3-coupling reaction of isovaleraldehyde, a variety of aniline derivatives and triisopropylsilylacetylene. Reaction conditions: isovaraldehyde $(0.265 \mathrm{mmol})$, aniline derivative (0.265 mmol), triisopropylsilylacetylene $(0.265 \mathrm{mmol})$, catalyst $2(5 \mathrm{~mol} \%)$ in C6D6 $(0.4 \mathrm{~mL})$ at 80 oC. 
With the intention of probing the versatility of complex 2 as a catalyst for the hydroalkynylation of imines, the influence of more sterically hindered aldehydes was explored (Scheme 3). Cyclohexylaldehyde was tested under the conditions previously described for isovaleraldehyde with triisopropylsilylacetylene and aniline derivatives as the coupling partners. The desired propargylamines 7a-h were formed in excellent yields (91-97\%). Surprisingly, shorter reaction times were required compared to reactions that use isovaraldehyde as starting material, which could be considered less sterically hindered (6a-f vs 7a-f). In contrast, reactions with aniline and 3,4,5-trimethoxyaniline exhibit poor reactivity and require long reaction times ( $36 \%$ and $52 \%$ yield respectively), which might be due to orthometalation.

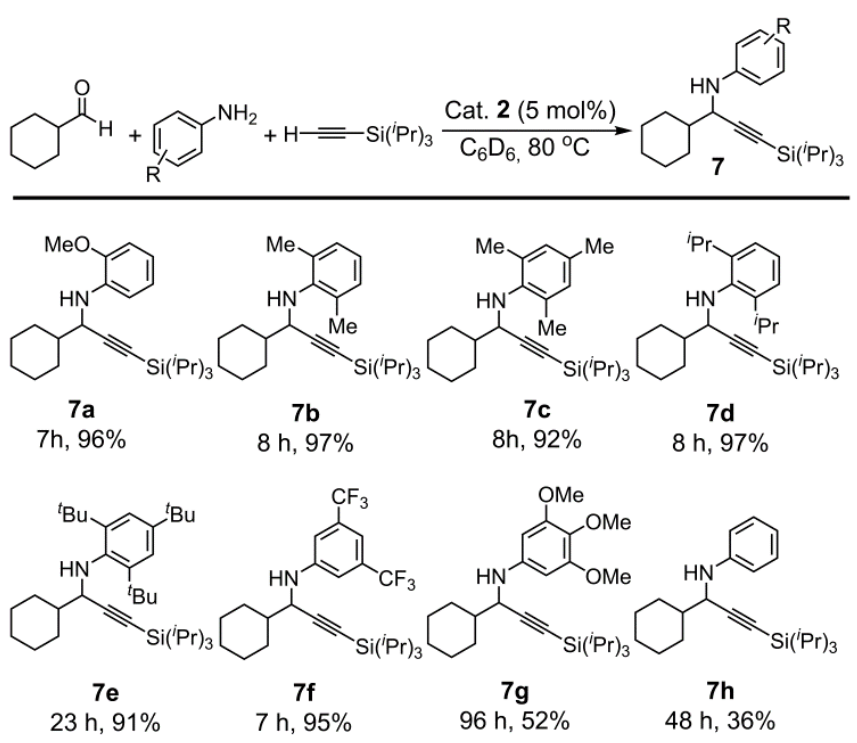

Scheme 3. A3-coupling reaction from cyclohexanecarboxaldehyde, a variety of aniline derivatives and a bulky alkyne. Reaction conditions: cyclohexanecarboxaldehyde $(0.265 \mathrm{mmol})$, aniline derivative $(0.265 \mathrm{mmol})$, triisopropylsilylacetylene $(0.265 \mathrm{mmol})$, catalyst $2(5 \mathrm{~mol} \%)$ in C6D6 (0.4 mL) at 80 oC.

The effect exerted by the aliphatic substituent (R) at the RCHO boosted our interest on how the nature of the aldehyde influences the efficiency of the reaction. Therefore, a range of unand branched aliphatic aldehydes was tested with o-anisidine or 2-fluoroaniline and triisopropylsilylacetylene (Scheme 4). 


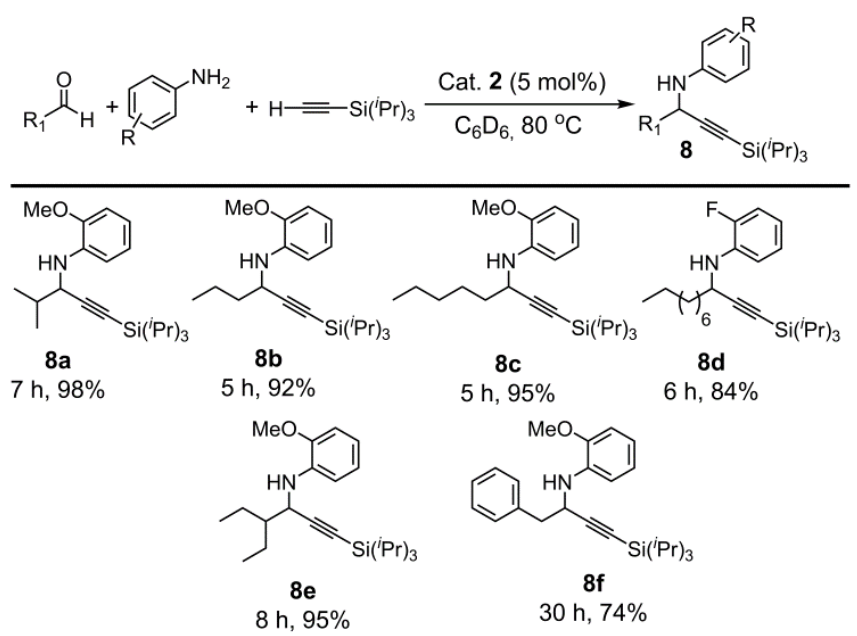

Scheme 4. Influence of the aldehyde. Reaction conditions: aldehyde derivative $(0.265 \mathrm{mmol})$, aniline derivative $(0.265 \mathrm{mmol})$, triisopropylsilylacetylene $(0.265 \mathrm{mmol})$, catalyst $2(5 \mathrm{~mol} \%)$ in C6D6 (0.4 mL) at 80 oC.

The reactions are usually completed within 5-30 h. It seems that branched-aldehydes such as isobutyraldehyde and 2-ethylbutanal are the most reactive aldehydes, giving the products $8 \mathrm{a}$ and $8 \mathrm{e}$ with yields up to $98 \%$. Un-branched aldehydes led to propargylamines $8 \mathrm{~b}$-d in good to excellent yields. Propargylamine $8 \mathrm{f}$ derived from benzylacetaldehyde required prolonged heating and was obtained in moderate yields (74\%).

In addition to the screening of aliphatic aldehydes, the reactivity with the most sterically hindered aniline at our disposal, namely 2,4,6-tert-butylaniline, has also been investigated under analogous conditions to the ones described above (Scheme 5).

In all cases, the corresponding products 9a-d were formed in high yields (87-94\%) and short reaction times, which demonstrates the tolerance of this methodology to highly hindered substrates.

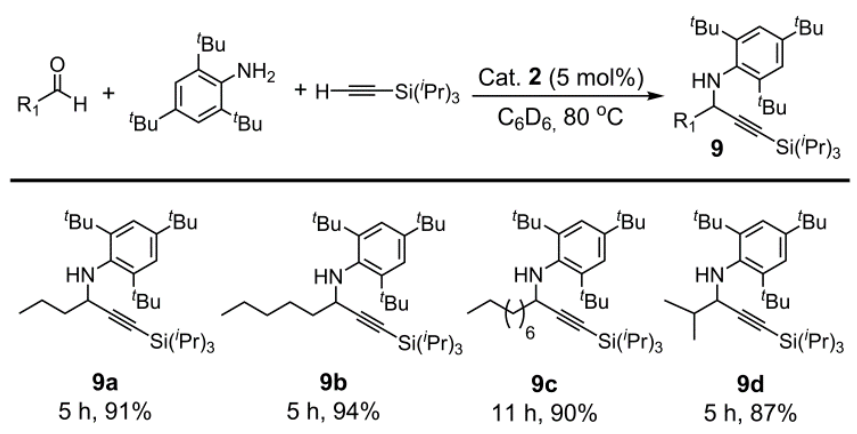

Scheme 5. Substrate scope based on a bulky aniline substitution. Reaction conditions: aldehyde derivative $(0.265 \mathrm{mmol}), 2,4,6$-tri-tert-butylaniline $(0.265 \mathrm{mmol})$,

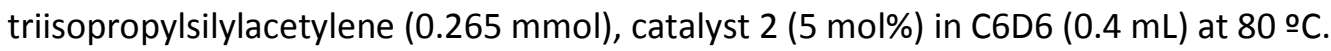

The dearth of detailed mechanistic information available for A3-coupling reactions in the literature prompted us to perform several stoichiometric experiments that would help to disclose the nature of the active species and the intermediates involved in the reaction mechanism (Scheme 6). Treatment of complex 2 with isovaleraldehyde at room temperature 
led to the formation of the bis-carbonyl complex $[\mathrm{RhCl}(\mathrm{CO}) 2 \mathrm{IPr}]$ (3), probably via decarbonylation of the aldehyde.[13] This complex has been previously prepared by placing [RhCl(COD)IPr] under an atmosphere of carbon monoxide.[14] Remarkably, when 2 equivalents of isovaleraldehyde and 2 equivalents of 2,4,6-trimethylaniline were added to 2 in toluene, a new complex that presents a coordinated amine is formed instead of 3 . The formulation of the new complex, $[\mathrm{RhCl}(\mathrm{CO}) \operatorname{IPr}(\mathrm{MesNH} 2)]$ (4) (MesNH2 = 2,4,6trimethylaniline), has been proposed based on elemental analysis, NMR and IR spectroscopy. The $1 \mathrm{H}$ NMR spectra show the expected set of resonances for the MesNH2 moiety. A broad signal assigned to the coordinated $-\mathrm{NH} 2$ moiety appears at $\delta 3.93 \mathrm{ppm}$, whereas the resonance corresponding to the free $-\mathrm{NH} 2$ from 2,4,6-trimethylaniline was highfield-shifted to $\delta 2.95 \mathrm{ppm}$. The $13 \mathrm{C}\{1 \mathrm{H}\}$-APT NMR spectrum displays two doublets at $\delta 185.7$ (JC-Rh $=82.3$ $\mathrm{Hz})$ and $181.6 \mathrm{ppm}(\mathrm{JC}-\mathrm{Rh}=55.6 \mathrm{~Hz}$ ) corresponding to the $\mathrm{CO}$ ligand trans to the chloride and the carbene carbon atom, respectively. Interestingly, the absence of Rh-C coupling for the carbon atoms of the aromatic ring of the aniline derivative (see spectra in Supporting Information) confirms the coordination by the nitrogen atom and discards an interaction by the $\pi$-system of the aromatic ring. In the IR spectrum of the resulting pale yellow solid, a single uCO band is observed at $1949 \mathrm{~cm}-1$.

When 4 is reacted with an excess of isovaleraldehyde ( 3 eq.) and 2,4,6-trimethylaniline (3 eq.) at $40{ }^{\circ} \mathrm{C}$ for $30 \mathrm{~min}$, imine complex [ $\left.\mathrm{RhCl}(\mathrm{CO}) \operatorname{IPr}(\mathrm{MesN}=\mathrm{CHCH} 2 \mathrm{CH}(\mathrm{CH} 3) 2)\right](5)$ is formed in ca. $60 \%$ conversion. An increase of the temperature to $80 \stackrel{\circ}{ } \mathrm{C}$ does not result in a noticeably improved conversion, which may suggest that complexes 4 and 5 are in equilibrium under these reaction conditions. Complex 5 was characterised in situ by NMR spectroscopy. The $1 \mathrm{H}$ NMR spectrum showed a triple of doublets at $\delta 8.58 \mathrm{ppm}(\mathrm{JH}-\mathrm{H}=5.7, \mathrm{JRh}-\mathrm{H}=1.3 \mathrm{~Hz}$ ) attributed to the coordinated imine hydrogen $-\mathrm{N}=\mathrm{CH}$. The signal corresponding to the free $\mathrm{N}=\mathrm{CH}$ appears at $\delta 7.60 \mathrm{ppm}$ as a triplet $(\mathrm{JH}-\mathrm{H}=6.1 \mathrm{~Hz})$. The $13 \mathrm{C}\{1 \mathrm{H}\}-\mathrm{APT}$ NMR shows the presence of two sets of doublets at $\delta 185.3(\mathrm{JRh}-\mathrm{C}=82.6 \mathrm{~Hz})$ and $182.7 \mathrm{ppm}(\mathrm{JRh}-\mathrm{C}=51.9 \mathrm{~Hz})$, which are assigned to the coordinated carbonyl ligand and the carbene carbon atom, respectively. A singlet at $\delta 177.7 \mathrm{ppm}$ corresponds to the $-\mathrm{NCH}$ moiety, while the free imine formed in situ is observed at $\delta 166.6 \mathrm{ppm}$. Noteworthy, addition of alkyne to this mixture resulted in the formation of the corresponding propargylamine, even when the temperature was progressively increased from $183 \mathrm{~K}$.

Additionally, we found that complex 3 did not react with isovaleraldehyde (3 eq.) and 2,4,6trimethylaniline ( 3 eq.) in toluene- $\mathrm{d} 8$ at $40{ }^{\circ} \mathrm{C}$ to afford 5 , even under forcing conditions ( $80 \mathrm{oC}$ for $1 \mathrm{~h}$ ), probably due to the strong coordination of the $\mathrm{CO}$ ligands to the rhodium centre. 


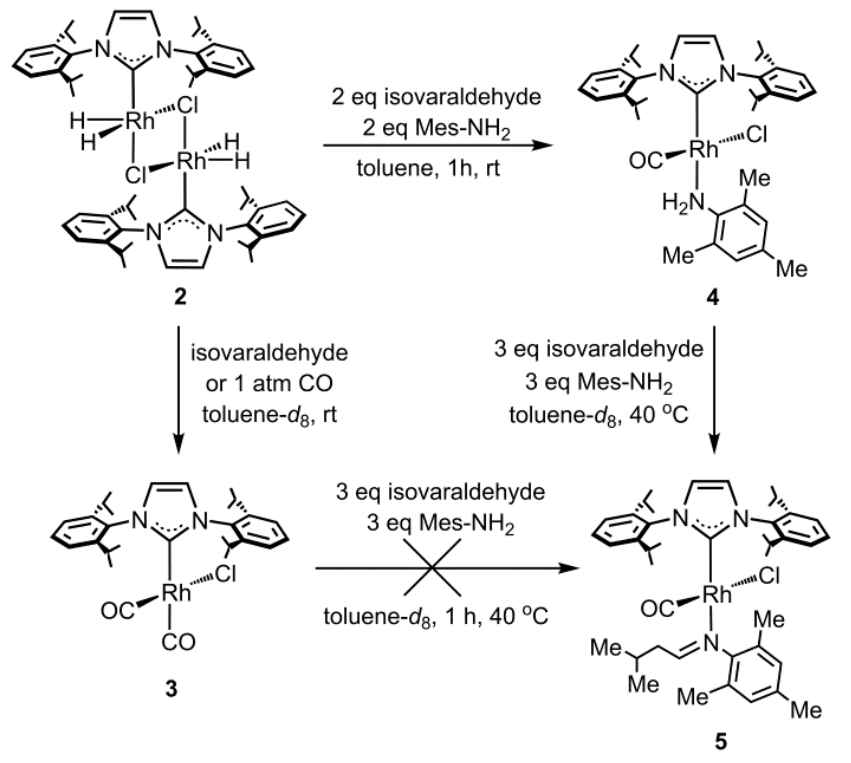

Scheme 6. Detected intermediates for the A3-coupling reaction.

The use of complexes 1-4 as catalysts for the A3-coupling reaction of isovaraldehyde, 2,4,6trimethylaniline and triisopropylsilyl acetylene provided interesting insights into the nature of the active species and the reaction mechanism (Figure 1). The reactions were carried out in NMR tubes using toluene-d8 as solvent with a 5 mol\% of catalyst (1) and kept at $80 \circ \mathrm{C}$. With the exception of complex 3 , all catalysts led to excellent conversions. When the reaction was conducted with complex 4 , the conversion was almost identical to that found for 2 , giving turnover frequencies at $50 \%$ conversion (TOF1/2) of $21 \mathrm{~h}-1$. The dimer $[\mathrm{Rh}(\square \mathrm{Cl})(\mathrm{COE})(\operatorname{IPr})] 2$ (1) was less efficient, with a TOF $1 / 2$ of $8 \mathrm{~h}-1$ and a maximum conversion of $73 \%$. This behaviour can be explained by the ability of the COE ligand to re-enter the coordination sphere, thus hindering the access of substrates to the active site.[11a] The rhodium dicarbonyl complex 3 , on the other hand, was virtually inactive under the same reaction conditions, which suggests that 3 is not the active species for the A3-coupling reaction.

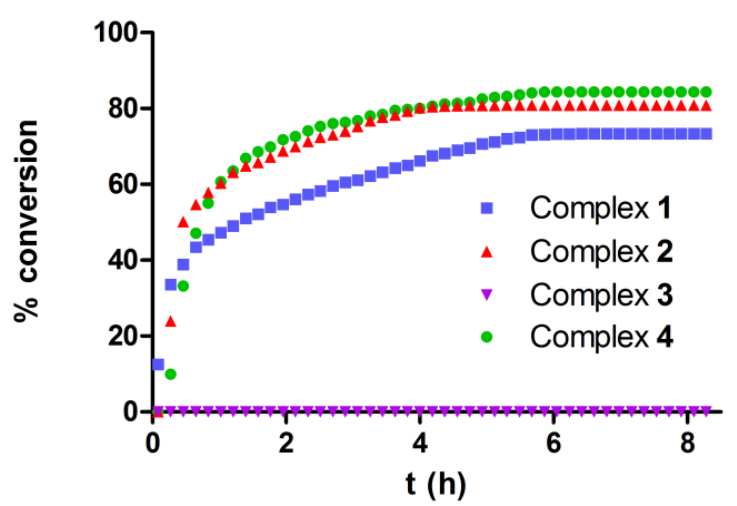

Fig 1. Catalysts used for the A3-coupling of isovaraldehyde, o-anisidine and triisopropylsilylacetylene in in C6D6 $(0.4 \mathrm{~mL})$ at $80{ }^{\circ} \mathrm{C}$.

According to the experimental data complex 5 may be postulated as the most plausible active species since imine coordination seems to be predominant compared to that of amines, in fact, 5 is formed in a $60 \%$ yield in the presence of 3 equivalents of amine and aldehyde. The 
higher imine to complex ratio under catalytic conditions would probably favour the formation of 5 against 4, nevertheless, the presence of the latter should not be discarded. Consequently, an active species containing a coordinated amine trans to the NHC is also conceivable, but less likely than its analogous imine derivative. At first glance, a catalytic cycle that entails (i) interaction of the alkyne with the metal centre followed by (ii) oxidative addition of the $\mathrm{C}-\mathrm{H}$ bond, (iii) insertion of the imine into the $\mathrm{Rh}-\mathrm{C}$ bond and, finally, (iv) elimination of the propargylamine (Scheme 7; pathway A), would seem a plausible postulation.

In order to shed light into the reaction mechanism, a computational study at the DFT level using the B3LYP-D3/def2-SVP methodology has been carried out on a model system of complex 5, where the diisopropylphenyl wingtip groups and the imine substituents were replaced by phenyl moieties. The Gibbs energy profile for the hydroalkynylation of imines $(R=$ $\mathrm{Ph}$ ) by trimethylsilylacetylene is shown in Figure 2 .

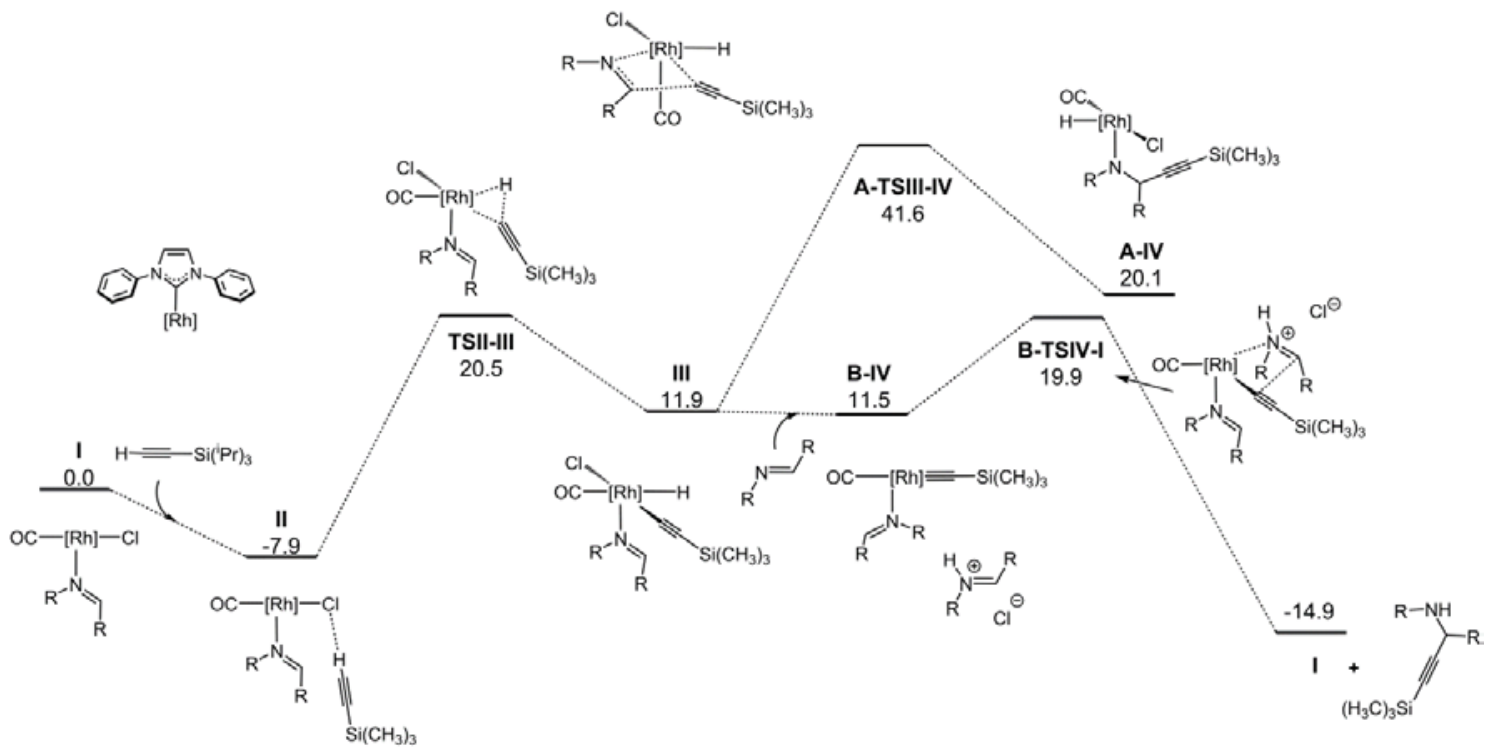

Fig. 2. Gibbs energy profile (in $\mathrm{kcal} / \mathrm{mol}$, relative to I and isolated molecules) for the hydroalkynylation of imines $(\mathrm{R}=\mathrm{Ph}$ ) by trimethylsilylacetylene catalysed by I (complex 5). 


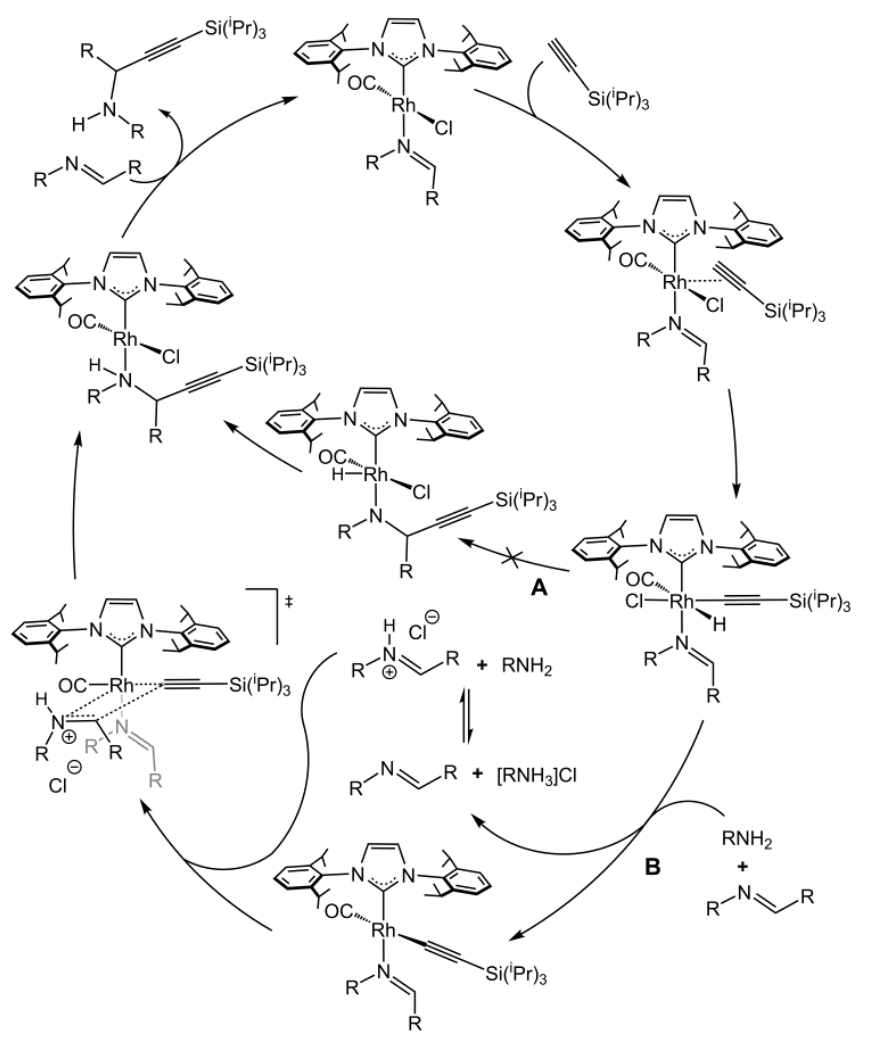

Scheme 7. Intramolecular (A) and Intermolecular (B) catalytic cycle postulated for the A3coupling reaction.

The proposed reaction mechanism would entail as first step the interaction of the alkyne molecule with I (complex 5) to form adduct II via a hydrogen bond interaction with the chloride ligand.

Subsequently, oxidative addition of the $\mathrm{C}-\mathrm{H}$ bond to the metal centre would take place via TSII-III to afford octahedral Rh(III) intermediate (III). This step would be the rate determinig step, with an activation barrier of $28.4 \mathrm{kcal}$ mol-1. At this stage, the theoretical calculations show that the migratory insertion of the imine into the $\mathrm{Rh}-\mathrm{C}$ bond is not possible due to the high activation barrier obtained for A-TSIII-IV, which presents a relative energy of $41.6 \mathrm{kcal}$ mol-1, unaffordable at the experimental conditions. The instability of A-TSIII-IV can be explained by the perpendicular orientation of the $\mathrm{N}-\mathrm{C} \pi$ bond and the Rh-C axis. Thus, this inefficient orbital overlapping in the transition state requires decoordination of the imine to afford a viable transition state (see Supporting Information).

A plausible alternative (pathway B) would entail the approximation of a second molecule that deprotonates intermediate III, with concomitant formation of the iminium (or amonium) salt, release of the chloride anion, and formation of the $\mathrm{Rh}(\mathrm{I})$ intermediate B-IV. In this regard, it must be noted that abundant free imine has been observed in the reaction mixture during catalysis at 80 ㅇ. A $1 / 4$ ratio imine/amine is present at the initial stages, increasing as the reaction proceeds, which indicates that the imine in solution is in equilibrium with the aldehyde and amine. The similar pKa of imines and primary aromatic amines implies that an acid-base equilibrium should lead to the co-existence of $\mathrm{RNH} 2,[\mathrm{RNH} 3] \mathrm{Cl}, \mathrm{R}^{\prime} \mathrm{N}=\mathrm{CHR}$ " and $\left[\mathrm{R}^{\prime} \mathrm{NH}=\mathrm{CHR} "\right] \mathrm{Cl}$ throughout the catalytic cycle. Nevertheless, the only substrate interaction that 
permits the reaction to proceed successfully is that of the protonated imine. Then, B-IV intermediate in presence of protonated imine would undergo migratory insertion via B-TSIV-I (Figure 2), with a relative energy of $19.9 \mathrm{kcal} \mathrm{mol-1}$. Finally, the release of the propargylamine and the regeneration of the active species is favoured thermodynamically, resulting in an exergonic reaction $(14.8 \mathrm{kcal} / \mathrm{mol})$.

To conclude, it is worth noting that the proposed mechanism is consistent with that previously reported by us for the hydroalkynylation of imines catalysed by a bimetallic $\operatorname{Ir}(I I)$ complex.[7]

Conclusions

In summary, we have developed a three-component coupling reaction of aliphatic aldehydes, aniline derivatives and triisopropylsilylacetylene catalysed by a Rh-NHC complex that operates under relatively mild conditions. This catalytic system has allowed us to generate a library of new propargylamines in good to excellent yields, which may be utilised as building blocks for the preparation of a wide variety of value-added products by the deprotection of the silyl moieties. Moreover, we have proposed a catalytic cycle that sheds light on the hitherto scarcely studied mechanism for the hydroalkynylation of imines. Remarkably, theoretical calculations reveal that the catalytic cycle cannot proceed by direct migratory insertion of the imine into the Rh-alkynyl bond as it would be expected for a "classical" mechanism. Instead, reductive elimination of $\mathrm{HCl}$ assisted by the free imine (or amine) in the reaction mixture and formation of a $\mathrm{Rh}(\mathrm{I})$ intermediate must occur previous to the migratory insertion of the into the Rh-C bond. In summary, this novel reaction mechanism entails (i) oxidative addition of the alkyne's C-H bond, (ii) protonation of "free" imine, (iii) insertion of the iminium cation into the alkynyl ligand and, finally, liberation of the corresponding propargylamine with concomitant regeneration of the active species.

Experimental Section

General

All reactions and manipulations were performed under an Ar atmosphere by using Schlenktype techniques. Hexane was dried by standard procedures and distilled under argon before to use or obtained oxygen and water-free from a Solvent Purification System (Innovative Technologies). The starting complexes $[\mathrm{Rh}(\mu-\mathrm{Cl})(\mathrm{IPr})(\mathrm{coe})] 2$ and $[\mathrm{Rh}(\mu-\mathrm{Cl})(\mathrm{H}) 2(\mathrm{IPr})] 2$ were prepared following the procedures described in the literature.[10,14] All other chemicals were used as purchased from Sigma-Aldrich, Merck and Acros. $1 \mathrm{H}$ and $13 \mathrm{C}$ spectra were recorded either on a Bruker ARX 300 (300 and $75 \mathrm{MHz}$ respectively) or Bruker Avance $400 \mathrm{MHz}$ (400 and $121 \mathrm{MHz}$ respectively) spectrometers using TMS as the internal reference. All chemical shifts $(\delta)$ are reported in ppm and coupling constants $(J)$ are reported in $\mathrm{Hz}$ to apparent peak multiplicities. $1 \mathrm{H}-1 \mathrm{H}$ COSY, $13 \mathrm{C}$ attached proton test (APT), 1H/13C HSQC and $1 \mathrm{H} / 13 \mathrm{C} \mathrm{HMB}$ sequences were used to help the assignments of the $1 \mathrm{H}$ and $13 \mathrm{C}$ spectra. $\mathrm{C}, \mathrm{H}$, and $\mathrm{N}$ analyses were carried out in a Perkin-Elmer $2400 \mathrm{CHNS/O}$ analyzer. GC/MS analyses were recorded on an Agilent 5973 mass selective detector interfaced to an Agilent 6890 series gas chromatograph system using a HP-5MS $5 \%$ phenyl methylsiloxane column $(30 \mathrm{~m} \times 250 \mathrm{~mm}$ with a $0.25 \mathrm{~mm}$ film thickness). 
[RhCl(CO)IPr(MesNH2)] (4). A solution of [RhH2( $\mu-\mathrm{Cl})(\operatorname{IPr})] 2$ (2) (200 mg, $0.379 \mathrm{mmol}), 2,4,6-$ trimethylaniline $(80 \mu \mathrm{L}, 1.5 \mathrm{eq}, 0.568 \mathrm{mmol})$, isovaleraldehyde $(81 \mu \mathrm{L}, 2.0 \mathrm{eq}, 0.757 \mathrm{mmol})$ in toluene was stirred for $1 \mathrm{~h}$ at room temperature. After filtration through Celite ${ }^{\circledR}$, the solvent was evaporated to dryness. Addition of hexane induced the precipitation of a pale yellow solid that was washed with hexane $(3 \times 5 \mathrm{~mL})$ and dried in vacuum. Yield: $(45 \%, 117 \mathrm{mg})$. IR $(\mathrm{u} \mathrm{cm}$ 1): 2964, 2279, 1949(CO), 1486, 1466, 1329, 1034, 1023, 800, 754. 1H NMR (400 MHz, C6D6, $298 \mathrm{~K}$ ): $\delta 7.30$ (dd, JH-H = 8.9, 6.4, 2H, Hp-IPr), 7.22 (dd, JH-H = 8.9, 6.4, 4H, Hm-IPr), 6.67 (s, $2 \mathrm{H},=\mathrm{CHN}$ ), 6.41 (s, 2H, Hm-Ph), 3.93 (s, 2H, NH2), 3.23 (sept, JH-H = 6.5, 4H, CHMelPr), 1.91 (s, 3H, p-Me), 1.80 (s, 6H, o-Me), 1.52 and 1.06 (both d, JH-H = 6.5, 24H, CHMeIPr). 13C\{1H\}-APT NMR plus HSQC and HMBC (100 MHz, C6D6, $298 \mathrm{~K}$ ): $\delta 185.7$ (d, JC-Rh = 82.3, CO-Rh), 181.6 (d, JC-Rh = 55.6, CIPr-Rh), 146.6 (s, Cq-IPr), 139.2 (s, Cq-Ph), 136.6 (s, CqN), 131.7 (s, Cq-pMe), 129.8 (s, Cp-IPr), 128.7 (s, Cm-Ph), 125.8 (s, Cq-oMe), 123.8 (s, Cm-IPr), 28.7 (s, CHMelPr), 26.2 and 22.6 (both s, CHMeIPr), 20.2 (s, p-Me), 17.8 (s, o-Me). Anal. Calc. for C37H50CIN3ORh: C, 64.30; H, 7.29; N, 6.08. Found: C, 64.38; H, 7.29; N 6.24.

[RhCl(CO)IPr(MesN=CHCH2CH(CH3)2)] (5). A solution of $4(30 \mathrm{mg}, 0.043 \mathrm{mmol})$ in toluene-d8 ( $0.5 \mathrm{~mL}, \mathrm{NMR}$ tube) was treated with 2,4,6-trimethylaniline (18 $\mu \mathrm{L}, 3 \mathrm{eq}, 0.130 \mathrm{mmol})$ and isovaleraldehyde ( $14 \mu \mathrm{L}, 3 \mathrm{eq}, 0.130 \mathrm{mmol})$ and heated at $40{ }^{\circ} \mathrm{C}$ for $30 \mathrm{~min}$. After this time, the resulting solution was analyzed at room temperature by NMR spectroscopy. $1 \mathrm{H}$ NMR (400 $\mathrm{MHz}, \mathrm{C6D6}, 298 \mathrm{~K}$ ): $\delta 8.58(\mathrm{td}, \mathrm{JH}-\mathrm{H}=5.6,1.3,1 \mathrm{H}, \mathrm{N}=\mathrm{CH}), 7.31(\mathrm{t}, \mathrm{JH}-\mathrm{H}=7.2,2 \mathrm{H}, \mathrm{Hp}-\mathrm{IPr}), 7.23$ (d, JH-H = 7.2, 4H, Hm-IPr), $6.74(\mathrm{~s}, 2 \mathrm{H},=\mathrm{CHN}), 6.63$ (s, 2H, Hm-Ph), 3.27 (sept, JH-H = 6.7, 4H, CHMelPr), 2.06 (s, 3H, p-Me), 1.95 (s, 6H, o-Me), 1.52 and 1.10 (both d, JH-H = 6.7, 24H, CHMeIPr), 1.45 (dsept, JH-H = 6.4, 6.3, 1H, CHMe), 1.34 (dd, JH-H =6.3, 5.6, 2H, CH2), 0.57 (d, $\mathrm{JH}-\mathrm{H}=6.4,6 \mathrm{H}, \mathrm{CHMe}) .13 \mathrm{C}\{1 \mathrm{H}\}-\mathrm{APT}$ NMR plus HSQC and HMBC (100 MHz, C6D6, $298 \mathrm{~K}): \delta$ 185.3 (d, JC-Rh = 82.6, CO-Rh), 182.7 (d, JC-Rh = 51.9, CIPr-Rh), 177.7 (s, N=CH), 147.2 (s, Cq$\mathrm{Ph}$ ), 147.0 (s, Cq-IPr), 137.0 (s, CqN), 134.2 (s, Cq-pMe), 129.9 (s, Cp-IPr), 129.0 (s, Cm-Ph), 127.8 (s, Cq-oMe), 124.0 (s, Cm-IPr), 123.9 (s, =CHN), 40.8 (s, CH2), 29.0 (s, CHMelPr), 26.5 and 23.1 (both s, CHMeIPr), 26.4 (s, CHMe), 22.4 (s, CHMe), 20.4 (s, p-Me), 18.5 (s, 2o-Me).

Synthesis of N-Propargylamines.

An NMR tube was charged with $0.01 \mathrm{mmol}$ of catalyst, $0.2651 \mathrm{mmol}$ of aniline derivative, $0.2651 \mathrm{mmol}$ of aldehyde and $0.2651 \mathrm{mmol}$ of triisopropylsilylacetylene in $0.4 \mathrm{~mL}$ of C6D6. After sealing it under an argon atmosphere the resulting solution was heated at $80{ }^{\circ} \mathrm{C}$ and monitored by NMR. Reaction product formation was monitored at periodic times and the conversion was quantified by the integration of the $1 \mathrm{H}$ NMR signals of imine formed in situ and the products.

$\mathrm{N}$-(1-(triisopropylsilyl)-5-methylhex-1-yn-3-yl)-2-methoxybenzenamine.

1H NMR (400 MHz, C6D6, 298 K): $\delta 6.78$ (td, JH-H = 8.3, 1.2, 1H, Hm1-Ph), 6.66 (td, JH-H = 7.6, 1.4, 1H, Hp-Ph), 6.51 (d, JH-H =8.3, 1.2, 1H, Ho-Ph), 6.48 (dd, JH-H = 7.6, 1.4, 1H, Hm2-Ph), 4.29 (t, JH-H = 7.2, 1H, CHNH), 3.32 (s, 3H, OMe), 3.11 (br, 1H, CHNH), 1.89 (m, 1H, CHMe), 1.53 (m, $2 \mathrm{H}, \mathrm{CH} 2$ ), 1.13 (d, JH-H = 6.2, 18H, SiCHMe), 1.03 (sept, JH-H = 6.2, 3H, SiCHMe), 0.82 and 0.81 (both d, JH-H =6.8, 6H, CHMe). 13C\{1H\}-APT NMR plus HSQC and HMBC (100 MHz, C6D6, 298 K): $\delta 146.7$ (s, Cq-OMe), 136.7 (s, Cq-Ph), 121.1 (s, Cm1-Ph), 117.8 (s, Cp-Ph); 114.7 (s, Cm2$\mathrm{Ph}), 110.5$ (s, C1), 110.4 (s, Co-Ph), 84.0 (s, C2), 61.1 (s, CHNH), 54.7 (s, OMe), 46.9 (s, CH2), 
24.9 (s, CHMe), 22.4 and 22.1 (both s, CHMe), 18.4 (s, SiCHMe), 11.2 (s, SiCHMe). GC-MS m/z: $373(\mathrm{M}+), 358(\mathrm{M}+\mathrm{-}-\mathrm{Me}), 342,316,286,258,245,229,216,202,178$.

$\mathrm{N}$-(1-(triisopropylsilyl)-5-methylhex-1-yn-3-yl)-2,6-dimethylbenzenamine.

1H NMR (400 MHz, C6D6, 298 K): $\delta 6.99$ (d, JH-H = 7.5, 2H, Hm-Ph), 6.78 (t, JH-H = 7.5, 1H, Hp$\mathrm{Ph}), 4.41(\mathrm{t}, \mathrm{JH}-\mathrm{H}=7.4,1 \mathrm{H}, \mathrm{CHNH}), 2.87(\mathrm{br}, 1 \mathrm{H}, \mathrm{CHNH}), 2.18$ (s, 6H, MelMes), $2.01(\mathrm{~m}, 1 \mathrm{H}$, $\mathrm{CHMe}$ ), $1.68(\mathrm{~m}, 2 \mathrm{H}, \mathrm{CH} 2), 1.22(\mathrm{~d}, \mathrm{JH}-\mathrm{H}=6.5,18 \mathrm{H}, \mathrm{SiCHMe}), 1.14$ (sept, JH-H = 6.5, 3H, SiCHMe), 0.93 and 0.92 (both d, JH-H = 7.5, 6H, CHMe). 13C\{1H\}-APT NMR plus HSQC and HMBC (100 MHz, C6D6, 298 K): $\delta 151.4$ and 126.1 (both s, Cq-Ph), 128.0 (s, Cm-Ph), 117.9 (s, $\mathrm{Cp}-\mathrm{Ph}$ ), 110.7 (s, C1), 83.8 (s, C2), 60.9 (s, CHNH), 47.0 (s, CH2), 24.7 (s, CHMe), 22.4 and 22.3 (both s, CHMe), 18.4 (s, SiCHMe), 18.3 (s, MelMes), 11.3 (s, SiCHMe). GC-MS m/z: $371(\mathrm{M}+$ ), 356 (M+ - Me), 329, 314, 308, 295, 260, 234, 218, 190, 174.

$\mathrm{N}$-(1-(triisopropylsilyl)-5-methylhex-1-yn-3-yl)-2,4,6-trimethylbenzenamine.

1H NMR (400 MHz, C6D6, $298 \mathrm{~K}$ ): $\delta 6.77$ (s, 2H, Hm-Ph), 4.30 (t, JH-H = 7.1, 1H, CHNH), 2.71 (br, 1H, CHNH), 2.18 (s, 3H, p-Me), 2.07 (s, 6H, o-Me), 1.85 (m, 1H, CHMe), 1.56 (m, 2H, CH2), 1.13 (d, JH-H = 6.1, 18H, SiCHMe), 1.01 (sept, JH-H =6.1, 3H, SiCHMe), 0.83 and 0.81 (both d, $\mathrm{JH}-\mathrm{H}=6.6,6 \mathrm{H}, \mathrm{CHMe}) .13 \mathrm{C}\{1 \mathrm{H}\}-\mathrm{APT}$ NMR plus HSQC and HMBC (100 MHz, C6D6, $298 \mathrm{~K}): \delta$ 149.1 (s, Cq-Ph), 128.7 (s, Cm-Ph), 126.3 and 121.1 (both s, Cq-Me), 110.5 (s, C1), 83.5 (s, C2), 60.8 (s, CHNH), 47.0 (s, CH2), 25.8 (s, CHMe), 22.1 and 22.0 (both s, CHMe), 20.2 (s, p-Me), 18.3 (s, o-Me), 18.2 (s, SiCHMe), 11.0 (s, SiCHMe). GC-MS m/z: 385 (M+), 342, 317, 300, 274, 248, 232, 204, 188, 162.

2,6-diisopropyl-N-(5-methyl-1-(triisopropylsilyl)hex-1-yn-3-yl)aniline.

1H NMR (400 MHz, C6D6, 298 K): $\delta 7.12$ (d, JH-H = 8.0, 2H, Hm-IPr), 6.95 (t, JH-H = 8.0, 1H, Hp$\mathrm{IPr}$ ), $4.40(\mathrm{t}, \mathrm{JH}-\mathrm{H}=7.3,1 \mathrm{H}, \mathrm{CHNH}$ ), $3.20(\mathrm{br}, 1 \mathrm{H}, \mathrm{CHNH}$ ), 2.77 (sept, JH-H = 7.4, 2H, CHMeIPr), $2.00(\mathrm{~m}, 1 \mathrm{H}, \mathrm{CHMe}), 1.64(\mathrm{~m}, 2 \mathrm{H} \mathrm{CH} 2), 1.25$ (d, JH-H = 7.4, 12H, CHMelPr), 1.21 (d, JH-H = 6.4, $18 \mathrm{H}, \mathrm{SiCHMe}$ ), 0.95 and 0.93 (both d, $\mathrm{JH}-\mathrm{H}=6.5,6 \mathrm{H}, \mathrm{CHMe}$ ), 1.16 (sept, $\mathrm{JH}-\mathrm{H}=6.4,3 \mathrm{H}$, SiCHMe). 13C $\{1 \mathrm{H}\}$-APT NMR plus HSQC and HMBC (100 MHz, C6D6, $298 \mathrm{~K}$ ): $\delta 140.7$ and 131.9 (both s, Cq-Ph), 122.7 (s, Cm-IPr), 118.7 (s, Cp-IPr), 110.8 (s, C1), 83.6 (s, C2), 61.0 (s, CHNH), 47.2 (s, CH2), 28.7 (s, CHMe), 27.9 (s, CHMelPr), 22.4 and 22.3 (both s, CHMe), 22.3 (s, CHMeIPr), 18.4 (s, SiCHMe), 11.2 (s, SiCHMe). GC-MS m/z: 427 (M+), 407, 384, 370, 359, 344, 330, 316, 290, 274, 260, 230, 202, 188.

2,4-6-tri-tert-butyl-N-(5-methyl-1-(triisopropylsilyl)hex-1-yn-3-yl)aniline.

1H NMR (400 MHz, C6D6, 298 K): $\delta 7.47$ (s, 2H, HPh), 4.40 (t, JH-H = 7.1, 1H, CHNH), 3.77 (br, $1 \mathrm{H}, \mathrm{CHNH}$ ), 1.66 (m, 2H, CH2), 2.02 (sept, JH-H = 7.0,1H, CHMe), 1.51 (s, 18H, o-tBu), 1.48 (s, $9 \mathrm{H}, \mathrm{p}-\mathrm{tBu}), 1.26(\mathrm{~d}, \mathrm{JH}-\mathrm{H}=6.1,18 \mathrm{H}, \mathrm{SiCHMe}), 1.15$ (sept, JH-H = 6.1, 3H, SiCHMe), 0.95 and 0.93 (both d, JH-H = 7.0, 6H, CHMe). 13C $\{1 \mathrm{H}\}$-APT NMR plus HSQC and HMBC (100 MHz, C6D6, $298 \mathrm{~K}$ ): $\delta 141.0$ (s, Cq-Ph), 139.7 and 133.5 (both s, Cq-Ph-tBu), 121.4 (s, CPh), 110.5 (s, C1), 84.1 (s, C2), 61.2 (s, CHNH), 47.1 (s, CH2), 34.6 and 34.4 (both s, Cq-tBu), 31.8 (s, p-tBu), 30.3 (s, o-tBu), 24.8 (s, CHMe), 22.3 and 22.2 (both s, CHMe), 18.5 (s, SiCHMe), 11.3 (s, SiCHMe). GC-MS m/z: 511 (M+ not observed), 454 (M+ - tBu), 439, 407, 381, 353, 337, 321, 295, 279, 261, 246, 230, 215, 189. 
N-(1-(triisopropylsilyl)-5-methylhex-1-yn-3-yl)-2,6-dimethylbenzenamine.

1H NMR (400 MHz, C6D6, 298 K): $\delta 7.18$ (s, 1H, Cp-Ph), 6.41 (s, 2H, Co-Ph), 4.29 (t, JH-H = 7.24, $1 \mathrm{H}, \mathrm{CHNH}), 2.94(\mathrm{br}, \mathrm{CHNH}), 1.89(\mathrm{~m}, 1 \mathrm{H}, \mathrm{CHMe}), 1.66(\mathrm{~m}, 2 \mathrm{H}, \mathrm{CH} 2), 1.25(\mathrm{~d}, \mathrm{JH}-\mathrm{H}=6.7,18 \mathrm{H}$, $\mathrm{SiCHMe}$ ), 1.16 (sept, JH-H = 6.7, 3H, SiCHMe), 0.86 and 0.84 (both d, JH-H = 7.5, 6H, CHMe). 13C\{1H\}-APT NMR plus HSQC and HMBC (100 MHz, C6D6, $298 \mathrm{~K}$ ): $\delta 147.7$ (s, Cq-Ph), 132.2 (q, $J C-F=31.8, C q-P h), 123.7$ (q, JC-F = 271.2, C-F), 113.7 (q, JC-F = 4.2, Co-Ph), 110.6 (q, JC-F = 4.1, $\mathrm{Cp}-\mathrm{Ph}$ ), 110.2 (s, C1), 84.3 (s, C2), 61.2 (s, CHNH), 47.2 (s, CH2), 24.7 (s, CHMe), 22.3 and 22.2 (both s, CHMe), 18.5 (s, SiCHMe), 11.2 (s, SiCHMe). GC-MS m/z: 479 (M+), 437, 422, 394, 378, 360, 338, 321, 304, 288, 272, 246, 229, 207, 181.

2-fluoro-N-(1-(triisopropylsilyl)-5-methylhex-1-yn-3-yl)benzenamine.

1H NMR (400 MHz, C6D6, 298 K): $\delta 6.90$ (dd, JH-F = 11.5, JH-H = 8.1, 1H, Hm1-Ph), 6.83 (dd, JH$\mathrm{H}=9.3,7.9,1 \mathrm{H}, \mathrm{Hm} 2-\mathrm{Ph}$ ), 6.55 (ddd, JH-H = 8.1, 7.9, JH-F = 5.0, $1 \mathrm{H}, \mathrm{Hp}-\mathrm{Ph}$ ), 6.45 (dd, JH-H = 9.3, JH-F = 7.6, 1H, Ho-Ph), 4.40 (t, JH-H = 7.5, 1H, CHNH), 3.01 (br, CHNH), 2.01 (m, 1H, CHMe), $1.65(\mathrm{~m}, 2 \mathrm{H}, \mathrm{CH} 2), 1.21$ (d, JH-H = 6.6, 18H, SiCHMe), 1.11 (sept, JH-H =6.6, 3H, SiCHMe), 0.95 and 0.93 (both d, JH-H = 6.6, 6H, CHMe). 13C\{1H\}-APT NMR plus HSQC and HMBC (100 MHz, C6D6, 298 K): $\delta 151.7$ (d, JC-F = 239.4, Cq-Ph), 134.8 (d, JC-F = 12.8, Cq-Ph), 124.3 (d, JC-F = 3.5, $\mathrm{Cm} 2-\mathrm{Ph}$ ), 118.1 (d, JC-F = 7.3, Cp-Ph), 116.7 (d, JC-F = 4.1, Co-Ph), 115.0 (d, JC-F = 19.0, Cm1$\mathrm{Ph}), 110.2$ (s, C1), 84.2 (s, C2), 61.1 (s, CHNH), 47.2 (s, CH2), 24.9 (s, CHMe), 22.4 and 22.2 (both s, CHMe), 18.4 (s, SiCHMe), 11.3 (s, SiCHMe). GC-MS m/z: 361 (M+), 349 (M+ - Me), 321, 304, 279, 265, 241, 232, 207, 192, 178.

N-(1-cyclohexyl-3-(triisopropylsilyl)prop-2-ynyl)-2-methoxybenzenamine.

1H NMR (400 MHz, C6D6, 298 K): $\delta 6.90$ (td, JH-H = 8.2, 1.1, 1H, Hm1-Ph), 6.79 (td, JH-H =7.7, 1.3, $1 \mathrm{H}, \mathrm{Hp}-\mathrm{Ph}$ ), 6.64 (dd, JH-H = 8.2, 1.1, 1H, Ho-Ph), 6.60 (dd, JH-H = 7.7, 1.3, 1H, Hm2-Ph), $4.16(\mathrm{~d}, \mathrm{JH}-\mathrm{H}=6.4,1 \mathrm{H}, \mathrm{CHNH}), 3.44(\mathrm{~s}, 3 \mathrm{H}, \mathrm{OMe}), 3.2(\mathrm{br}, 1 \mathrm{H}, \mathrm{CHNH}), 2.04,1.93,1.79,1.67$, and 1.60 (all br, 10H, CH2), 1.58 (m, 1H, CHcy), 1.25 (d, JH-H =6.7, 18H, SiCHMe), 1.17 (sept, $\mathrm{JH}-\mathrm{H}=6.7,3 \mathrm{H}, \mathrm{SiCHMe}) .13 \mathrm{C}\{1 \mathrm{H}\}-A P T$ NMR plus HSQC and HMBC (100 MHz, C6D6, $298 \mathrm{~K}): \delta$ 147.5 (s, Cq-OMe), 146.8 (s, Cq-Ph), 121.5 (s, Cm1-Ph), 118.2 (s, Cp-Ph), 114.9 (s, Cm2-Ph), 110.6 (s, Co-Ph), 109.5 (s, C1), 85.2 (s, C2), 67.5 (s, CHNH), 54.9 (s, OMe), 44.5 (s, CHcy), 29.0, 28.3, 26.9, 26.3, and 26.2 (all s, CH2), 18.8 (s, SiCHMe), 11.5 (s, SiCHMe). GC-MS m/z: 399 (M+), $384,371,356,316,272,245,221,178$.

$\mathrm{N}$-(1-cyclohexyl-3-(triisopropylsilyl)prop-2-ynyl)-2,6-dimethylbenzenamine.

1H NMR (400 MHz, C6D6, $298 \mathrm{~K}$ ): $\delta 7.0$ (d, JH-H = 7.4, 2H, Hm-Ph), 6.79 (t, JH-H = 7.4, 1H, Hp$\mathrm{Ph}), 4.16(\mathrm{~d}, \mathrm{JH}-\mathrm{H}=7.4,1 \mathrm{H}, \mathrm{CHNH}), 2.87(\mathrm{br}, 1 \mathrm{H}, \mathrm{CHNH}), 1.58(\mathrm{~m}, 1 \mathrm{H}, \mathrm{CHcy}), 2.03,1.91,1.86$, 1.79, and 1.67 (all m, CH2cy), 2.01 (s, 6H, Me), 1.25 (d, JH-H =6.5, 18H, SiCHMe), 1.14 (sept, $\mathrm{JH}-\mathrm{H}=6.5,3 \mathrm{H}, \mathrm{SiCHMe}) .13 \mathrm{C}\{1 \mathrm{H}\}-A P T$ NMR plus HSQC and HMBC (100 MHz, C6D6, $298 \mathrm{~K}): \delta$ 142.8 (s, Cq-Ph), 128.3 (s, Cm-Ph), 121.2 (s, Cq-Me), 117.9 (s, Cp-Ph), 109.3 (s, C1), 85.1 (s, C2), 67.3 (s, CHNH), 44.2 (s, CHcy), 29.3, 28.7, 28.1, 26.6, and 26.1 (all, CH2cy), 18.6 (s, SiCHMe), 17.2 (s, Me), 11.4 (s, SiCHMe). GC-MS m/z: 397 (M+), 383, 368, 323, 303, 279, 260, 234, 218, 190.

N-(1-cyclohexyl-3-(triisopropylsilyl)prop-2-ynyl)-2,4,6-trimethylbenzenamine. 
1H NMR (400 MHz, C6D6, 298 K): $\delta 6.80$ (s, 2H, Hm-Ph), 4.16 (d, JH-H = 5.9, 1H, CHNH), 2.70 (br, 1H, CHNH), 2.30 (m, 1H, CHcy), 2.28 (s, 3H, Mep-Ph), 2.03 (s, 6H, Meo-Ph), 2.02, 1.90, 1.78, 1.72, and 1.66 (all br, 10H, CH2cy), 1.25 (d, JH-H = 6.6, 18H, SiCHMe), 1.16 (sept, JH-H = 6.6, 3H, SiCHMe). 13C\{1H\}-APT NMR plus HSQC and HMBC (100 MHz, C6D6, $298 \mathrm{~K}$ ): $\delta 140.5$ (s, Cq$\mathrm{Ph}$ ), 129.0 (s, Cm-Ph), 126.5 and 121.2 (both s, Cq-Me), 109.3 (s, C1), 85.0 (s, C2), 67.0 (s, $\mathrm{CHNH}$ ), 44.3 (s, CHcy), 29.4, 28.7, 28.0, 26.6, and 26.0 (all s, CH2cy), 20.2 (s, Mep-Ph), 18.6 (s, SiCHMe), 11.3 (s, SiCHMe), 17.2 (s, Meo-Ph). GC-MS m/z: 411 (M+), 389, 368, 328, 300, 279, 264, 233, 209, 181.

N-(1-cyclohexyl-3-(triisopropylsilyl)prop-2-ynyl)-2,6-diisopropylbenzenamine.

1H NMR (400 MHz, C6D6, 298 K): $\delta 7.13$ (d, JH-H = 7.8, 2H, Hm-Ph), 6.96 (t, JH-H = 7.8, 1H, Hp$\mathrm{Ph}$ ), $4.16(\mathrm{~d}, \mathrm{JH}-\mathrm{H}=5.8,1 \mathrm{H}, \mathrm{CHNH}$ ), $3.04(\mathrm{br}, 1 \mathrm{H}, \mathrm{CHNH}), 2.78$ (sept, JH-H = 6.8, 2H, CHMelPr), 1.93, 1.82, 1.78, 1.65, and 1.29 (all m, CH2cy), 1.58 (m, 1H, CHcy), 1.25 (d, JH-H = 6.8, 12H, CHMelPr), 1.21 (d, JH-H =6.6, 18H, SiCHMe), 1.16 (sept, JH-H =6.6, 3H, SiCHMe). 13C\{1H\}-APT NMR plus HSQC and HMBC (100 MHz, C6D6, $298 \mathrm{~K}$ ): $\delta 140.5$ (s, Cq-Ph), 131.9 (s, Cq-Ph-o-IPr), 122.8 (s, Cm-Ph), 118.7 (s, Cp-Ph), 109.1 (s, C1), 85.2 (s, C2), 67.4 (s, CHNH), 44.4 (s, CHcy), 29.3, 28.8, 26.1, 26.0, and 25.5 (all m, CH2cy), 27.9 (s, CHMelPr), 18.6 (s, CHMelPr), 18.4 (s, SiCHMe), 11.3 (s, SiCHMe). GC-MS m/z: 453 (M+), 411, 385, 367, 359, 344, 316, 274, 260, 230, 204, 188, 172.

2,4,6-tri-tert-butyl-N-(1-cyclohexyl-3-(triisopropylsilyl)prop-2-ynyl)benzenamine.

1H NMR (400 MHz, C6D6, 298 K): $\delta 7.47$ (s, 2H, HPh), 4.18 (d, JH-H = 5.9, 1H, CHNH), 3.59 (br, $1 \mathrm{H}, \mathrm{CHNH}$ ), 2.05, 1.96, 1.83, 1.80, and 1.69 (all $\mathrm{m}, \mathrm{CH} 2 \mathrm{cy}$ ), 1.62 (m, 1H, CHcy), 1.52 (s, 18H, otBu), 1.48 (s, 9H, p- tBu), 1.27 (d, JH-H =6.5, 18H, SiCHMe), 1.22 (sept, JH-H =6.5, 3H, SiCHMe). 13C $\{1 \mathrm{H}\}-A P T$ NMR plus HSQC and HMBC (100 MHz, C6D6, $298 \mathrm{~K}$ ): $\delta 141.4$ (s, Cq-Ph), 139.2 (s, Cq-Ph-p-tBu), 133.7 (s, Cq-Ph-o-tBu), 121.7 (s, CPh), 109.2 (s, C1), 85.5 (s, C2), 67.3 (s, CHNH), 44.4 (s, CHcy), 34.8 and 34.6 (both s, Cq-tBu), 31.9 (s, Cp-tBu), 30.3 (s, Co-tBu), 28.9, 28.3, 26.9, 26.3, and 26.2 (all s, CH2cy), 18.9 (s, SiCHMe), 11.6 (s, SiCHMe). GC-MS m/z: 537 (M+ not observed), 507 (M+ - 2Me), 490, 476, 461, 419, 379, 357, 321, 261, 246, 215, 191.

$\mathrm{N}$-(1-cyclohexyl-3-(triisopropylsilyl)prop-2-ynyl)-3,5-bis(trifluoromethyl)benzenamine.

1H NMR (400 MHz, C6D6, 298 K): $\delta 7.15$ (s, 1H, Cp-Ph), 6.40 (s, 2H, Co-Ph), 4.02 (d, JH-H = 5.9, $1 \mathrm{H}, \mathrm{CHNH}$ ), 3.01 (s, 1H, CHNH), 1.89, 1.79, 1.67, 1.19, and 1.13 (all br, 10H, CH2cy), 1.42 (m, CHcy), 1.12 (d, JH-H = 6.0, 18H, SiCHMe), 1.04 (sept, JH-H =6.0, 3H, SiCHMe). 13C\{1H\}-APT NMR plus HSQC and HMBC (100 MHz, C6D6, $298 \mathrm{~K}$ ): $\delta 147.7$ (s, Cq-Ph), 132.1 (q, JC-F = 33.0, Cq-Ph), 123.8 (q, JC-F = 272.0, C-F), 113.6 (q, JC-F = 3.3, Co-Ph), 110.4 (q, JC-F = 4.0, Cp-Ph), 108.7 (s, C1), 85.4 (s, C2), 67.2 (s, CHNH), 44.1 (s, CHcy), 28.6, 27.9, 26.4, 25.9, and 25.8 (all s, CH2cy), 18.4 (s, SiCHMe), 11.2 (s, SiCHMe). GC-MS m/z: 505 (M+), 489, 462, 436, 422, 407, 389, 365, 321, 279, 255, 225, 09, 195, 181, 157.

N-(1-cyclohexyl-3-(triisopropylsilyl)prop-2-ynyl)-2,4,6-trimethoxybenzenamine.

1H NMR (400 MHz, C6D6, 298 K): $\delta 5.81$ (s, 2H, HPh), 4.24 (d, JH-H = 5.7, 1H, CHNH), 3.89 (s, $3 \mathrm{H}, \mathrm{Hp}-\mathrm{OMe}$ ), 3.54 (s, 6H, Ho-OMe), 3.41 (br, 1H, CHNH), 1.99, 1.96, 1.78, 1.26, and 1.22 (all m, $\mathrm{CH} 2 \mathrm{cy}), 1.65(\mathrm{~m}, 1 \mathrm{H}, \mathrm{CHcy}), 1.20(\mathrm{~d}, \mathrm{JH}-\mathrm{H}=6.2,18 \mathrm{H}, \mathrm{SiCHMe}), 1.14$ (sept, $\mathrm{JH}-\mathrm{H}=6.2,3 \mathrm{H}$, 
SiCHMe). 13C\{1H\}-APT NMR plus HSQC and HMBC (100 MHz, C6D6, $298 \mathrm{~K}$ ): $\delta 154.5$ and 143.3 (both s, Cq-OMe), 131.6 (s, Cq-Ph), 109.4 (s, C1), 93.3 (s, CPh), 84.9 (s, C2), 67.2 (s, CHNH), 60.3 (s, Cp-OMe), 55.6 (s, Co-OMe), 44.2 (s, CHcy), 29.5, 28.8, 26.7, 26.0, and 25.5 (all s, CH2cy), 18.4 (s, SiCHMe), 11.5 (s, SiCHMe). GC-MS m/z: 459 (M+ not observed), 416 (M+ - iPr), 401, 387, 357, 346, 322, 303, 288, 276, 162, 246, 233, 209, 177.

N-(1-cyclohexyl-3-(triisopropylsilyl)prop-2-ynyl)benzenamine.

1H NMR (400 MHz, C6D6, 298 K): $\delta 7.14$ (dd, JH-H = 7.8, 7.4, 2H, Hm-Ph), 6.80 (t, JH-H = 7.4, $1 \mathrm{H}, \mathrm{Hp}-\mathrm{Ph}$ ), 6.48 (d, JH-H = 7.8, 2H, Ho-Ph), 4.18 (d, JH-H = 5.7, 1H, CHNH), 3.36 (br, 1H, CHNH), 1.90, 1.73, 1.63, 1.32, and 1.20 (all m, CH2cy), 1.61 (m, 1H, CHcy), 1.22 (d, JH-H =6.0, 18H, SiCHMe), 1.16 (sept, JH-H = 6.0, 3H, SiCHMe). 13C\{1H\}-APT NMR plus HSQC and HMBC (100 MHz, C6D6, 298 K): $\delta 146.8$ (s, Cq-Ph), 128.9 (s, Cm-Ph), 118.4 (s, Cp-Ph), 114.8 (s, Co-Ph), 109.3 (s, C1), 84.9 (s, C2), 67.3 (s, CHNH), 44.0 (s, CHcy), 29.4, 26.6, 26.1, 25.9, and 25.5 (all s, CH2cy), 18.5 (s, SiCHMe), 11.5 (s, SiCHMe). GC-MS m/z: 369 (M+), 354 (M+ - Me), 326 (M+ iPr), 310, 298, 286, 270, 258, 242, 218, 202, 187, 178.

$\mathrm{N}$-(1-(triisopropylsilyl)-4-methylpent-1-yn-3-yl)-2-methoxybenzenamine.

1H NMR (400 MHz, C6D6, 298 K): $\delta 6.90$ (td, JH-H =8.0, 0.9, 1H, Hm1-Ph), 6.79 (td, JH-H =7.9, 1.2, 1H, Hp-Ph), 6.64 (dd, JH-H = 8.0, 0.9, Ho-Ph), 6.60 (dd, JH-H = 7.9, 1.2, 1H, Hm2-Ph), 4.15 (d, JH-H = 5.5, 1H, CHNH), 3.44 (s, 3H, OMe), 3.3 (br, 1H, CHNH), 1.88 (septd, JH-H = 6.7, 5.5, $1 \mathrm{H}, \mathrm{CHMe}$ ), 1.24 (d, JH-H =6.6, 18H, SiCHMe), 1.16 (sept, JH-H =6.6, 3H, SiCHMe), 1.13 and 1.06 (both d, JH-H = 6.7, 6H, CHMe). 13C $\{1 \mathrm{H}\}$-APT NMR plus HSQC and HMBC (100 MHz, C6D6, $298 \mathrm{~K}$ ): $\delta 147.3$ and 146.7 (both s, Cq-Ph), 121.3 (s, Cm1-Ph), 117.9 (s, Cp-Ph), 114.8 (s, Cm2$\mathrm{Ph}$ ), 110.5 (s, Co-Ph), 108.8 (s, C1), 85.1 (s, C2), 67.8 (s, CHNH), 54.6 (s, OMe), 34.7 (s, CHMe), 18.6 (s, SiCHMe), 18.1 and 17.2 (both s, CHMe), 11.3 (s, SiCHMe). GC-MS m/z: 359 (M+), 345, 329, 316, 202, 177.

N-(1-(triisopropylsilyl)hex-1-yn-3-yl)-2-methoxybenzenamine.

1H NMR (400 MHz, C6D6, 298 K): $\delta 6.90$ (td, JH-H =8.1, 1.3, 1H, Hm1-Ph), 6.79 (td, JH-H =7.7, 1.7, $1 \mathrm{H}, \mathrm{Hp}-\mathrm{Ph}$ ), 6.64 (dd, JH-H = 8.1, 1.3, 1H, Ho-Ph), 6.59 (dd, JH-H =7.7, 1.7, 1H, Hm2-Ph), $4.32(\mathrm{t}, \mathrm{JH}-\mathrm{H}=6.6,1 \mathrm{H}, \mathrm{CHNH}), 3.44(\mathrm{~s}, 3 \mathrm{H}, \mathrm{OMe}), 3.40(\mathrm{~s}, \mathrm{CHNH}), 1.70(\mathrm{~m}, 2 \mathrm{H}, \mathrm{CH} 2), 1.56(\mathrm{~m}$, $2 \mathrm{H}, \mathrm{CH} 2), 1.23$ (d, JH-H = 6.8, 18H, SiCHMe), 1.15 (sept, JH-H = 6.8, 3H, SiCHMe), $0.92(\mathrm{t}, \mathrm{JH}-\mathrm{H}=$ 7.3, 3H, Me). 13C\{1H\}-APT NMR plus HSQC and HMBC (100 MHz, C6D6, $298 \mathrm{~K}$ ): $\delta 147.3$ and 146.6 (both s, Cq-Ph), 121.3 (s, Cm1-Ph), 117.9 (s, Cp-Ph), 114.7 (s, Cm2-Ph), 110.5 (s, Co-Ph), 110.4 (s, C1), 84.0 (s, C2), 62.3 (s, CHNH), 54.8 (s, OMe), 40.2 (s, CH2), 18.7 (s, CH2), 18.6 (s, SiCHMe), 13.7 (s, Me), 11.2 (s, SiCHMe). GC-MS m/z: 359 (M+), 345, 331, 316, 301, 278, 262, 245, 221, 202, 178, 164.

$\mathrm{N}$-(1-(triisopropylsilyl)oct-1-yn-3-yl)-2-methoxybenzenamine.

1H NMR (400 MHz, C6D6, $298 \mathrm{~K}$ ): $\delta 6.89$ (td, JH-H =8.0, 1.5, 1H, Hm1-Ph), 6.78 (td, JH-H = 7.7, 1.7, $1 \mathrm{H}, \mathrm{Hp}-\mathrm{Ph}$ ), 6.64 (dd, JH-H = 8.0, 1.5, 1H, Ho-Ph), 6.60 (dd, JH-H = 7.7, 1.7, 1H, Hm2-Ph), $4.34(\mathrm{t}, \mathrm{JH}-\mathrm{H}=7.0,1 \mathrm{H}, \mathrm{CHNH}), 3.44(\mathrm{~s}, 3 \mathrm{H}, \mathrm{OMe}), 3.40(\mathrm{br}, 1 \mathrm{H}, \mathrm{CHNH}), 1.75,1.55,1.33$, and 1.29 (all m, 8H, CH2), 1.25 (d, JH-H =6.5, 18H, SiCHMe), 1.14 (sept, JH-H = 6.5, 3H, SiCHMe), $0.95(\mathrm{t}, \mathrm{JH}-\mathrm{H}=6.9,3 \mathrm{H}, \mathrm{Me}) .13 \mathrm{C}\{1 \mathrm{H}\}-\mathrm{APT}$ NMR plus HSQC and HMBC (100 MHz, C6D6, $298 \mathrm{~K})$ : 
$\delta 147.3$ and 146.6 (both s, Cq-Ph), 121.1 (s, Cm1-Ph), 118.0 (s, Cp-Ph), 114.8 (s, Cm2-Ph), 110.5 (s, Co-Ph), 110.4 (s, C1), 83.8 (s, C2), 62.4 (s, CHNH), 54.5 (s, OMe), 38.0, 31.4, 25.0, and 22.6 (all s, CH2), 18.6 (s, SiCHMe), 13.9 (s, Me), 11.4 (s, SiCHMe). GC-MS m/z: 387 (M+), 372 (M+ Me), 344, 316, 287, 272, 244, 229, 202, 187, 165.

2-fluoro-N-(1-(triisopropylsilyl)undec-1-yn-3-yl)benzenamine.

1H NMR (400 MHz, C6D6, $298 \mathrm{~K}$ ): $\delta 6.92$ (dd, JH-F = 11.5, JH-H = 8.2, 1H, Hm1-Ph), 6.83 (dd, JH$\mathrm{H}=9.1,8.1,1 \mathrm{H}, \mathrm{Hm} 2-\mathrm{Ph}$ ), 6.56 (ddd, JH-H = 8.2, 8.1, JH-F = 5.0,1H, Hp-Ph), 6.45 (dd, JH-H = 9.1, JH-F = 7.1, $1 \mathrm{H}, \mathrm{Ho}-\mathrm{Ph}), 4.35(\mathrm{t}, \mathrm{JH}-\mathrm{H}=6.6,1 \mathrm{H}, \mathrm{CHNH}), 3.20(\mathrm{br}, 1 \mathrm{H}, \mathrm{CHNH}), 2.75,2.26,2.25$, 1.76, 1.74, 1.56, 1.33 (all m, CH2), 1.25 (d, JH-H = 6.0, 18H, SiCHMe), 1.14 (sept, JH-H =6.0, 3H, SiCHMe), 1.01 (t, JH-H =6.8,3H, Me). 13C\{1H\}-APT NMR plus HSQC and HMBC (100 MHz, C6D6, 298 K): $\delta 151.9$ (d, JC-F = 232.0, Cq-Ph), 134.9 (d, JC-F = 14.8, Cq-Ph), 124.3 (d, JC-F = 4.7, Cm2-Ph), 118.0 (d, JC-F = 7.7, Cp-Ph), 116.6 (d, JC-F = 4.5, Co-Ph), 115.1 (d, JC-F = 18.7, Cm1$\mathrm{Ph}$ ), 110.0 (s, C1), 84.6 (s, C2), 62.5 (s, CHNH), 38.0, 32.0, 29.6, 28.7, 25.6, 25.3, and 22.9 (all m, CH2), 18.6 (s, SiCHMe), 14.0 (s, Me), 11.3 (s, SiCHMe). GC-MS m/z: 417 (M+), 397, 374, 357, 339, 318, 304, 286, 274, 254, 240, 228, 216, 203, 188.

N-(4-ethyl-1-(triisopropylsilyl)hex-1-yn-3-yl)-2-methoxybenzenamine.

1H NMR (400 MHz, C6D6, $298 \mathrm{~K}): \delta 6.89$ (td, JH-H = 7.9, 1.4, 1H, Hm1-Ph), 6.78 (td, JH-H =7.7, 1.8, $1 \mathrm{H}, \mathrm{Hp}-\mathrm{Ph}$ ), 6.64 (dd, JH-H = 7.9, 1.4, 1H, Ho-Ph), 6.60 (dd, JH-H = 7.7, 1.8, 1H, Hm2-Ph), $4.43(\mathrm{~d}, \mathrm{JH}-\mathrm{H}=5.2,1 \mathrm{H}, \mathrm{CHNH}), 3.44$ (s, 3H, OMe), $3.40(\mathrm{br}, 1 \mathrm{H}, \mathrm{CHNH}), 1.54(\mathrm{~m}, 4 \mathrm{H}, \mathrm{CH} 2), 1.52$ ( $\mathrm{m}, 1 \mathrm{H}, \mathrm{CHEt}$ ), 1.22 (d, JH-H = 6.6, 18H, SiCHMe), 1.13 (sept, JH-H =6.6, 3H, SiCHMe), 1.01 and 0.97 (both t, JH-H = 7.3, 6H, Me). 13C\{1H\}-APT NMR plus HSQC and HMBC (100 MHz, C6D6, $298 \mathrm{~K}$ ): $\delta 147.3$ and 146.6 (both s, Cq-Ph), 121.2 (s, Cm1-Ph), 117.9 (s, Cp-Ph), 114.9 (s, Cm2$\mathrm{Ph}$ ), 110.5 (s, Co-Ph), 109.3 (s, C1), 85.1 (s, C2), 64.8 (s, CHNH), 54.7 (s, OMe), 47.6 (s, CHEt2), 22.6 and 22.2 (both s, CH2), 18.6 (s, SiCHMe), 11.5 and 11.1 (both s, Me), 11.3 (s, SiCHMe). GCMS m/z: 387 (M+), 358, 344, 316, 276, 261, 237, 221, 205, 181.

$\mathrm{N}$-(4-(triisopropylsilyl)-1-phenylbut-3-yn-2-yl)-2-methoxybenzenamine.

1H NMR (400 MHz, C6D6, 298 K): $\delta 7.53$ (d, JH-H = 8.3, 2H, Ho-bz), 7.34 (m, 2H, Hm-bz), 6.89 (td, JH-H = 7.4, 1.3, 1H, Hm1-Ph), 6.80 (m, 1H, Hp-bz), 6.78 (td, JH-H =7.8, 1.7, 1H, Hp-Ph), 6.64 (dd, JH-H = 7.4, 1.3, 1H, Ho-Ph), $6.58(\mathrm{dd}, \mathrm{JH}-\mathrm{H}=7.8,1.7,1 \mathrm{H}, \mathrm{Hm} 2-\mathrm{Ph}), 4.53(\mathrm{t}, \mathrm{JH}-\mathrm{H}=6.7$, $\mathrm{CHNH}$ ), 3.34 (s, 3H, OMe), 3.11 (br, 1H, CHNH), 2.97 (d, JH-H = 6.7, CH2), 1.21 (d, JH-H = 6.3, 18H, SiCHMe), 1.17 (sept, JH-H =6.3, 3H, SiCHMe). 13C\{1H\}-APT NMR plus HSQC and HMBC (100 MHz, C6D6, 298 K): $\delta 147.0$ (s, Cq-OMe), 141.0 and 136.7 (both s, Cq-Ph), 129.3 (s, Co-bz), 128.5 (s, Cm-bz), 121.6 (s, Cp-bz), 121.2 (s, Cm1-Ph), 118.0 (s, Cp-Ph), 114.8 (s, Cm2-Ph), 110.6 (s, Co-Ph), 109.4 (s, C1), 85.7 (s, C2), 63.5 (s, CHNH), 54.7 (s, OMe), 44.3 (s, CH2), 18.4 (s, SiCHMe), 11.0 (s, SiCHMe). GC-MS m/z: 407 (M+, not observed), 392, 365, 317, 285, 228, 185, 165.

2,4,6-tri-tert-butyl-N-(1-(triisopropylsilyl)hex-1-yn-3-yl)benzenamine.

1H NMR (400 MHz, C6D6, $298 \mathrm{~K}): \delta 7.46$ (s, 2H, HPh), 4.32 (t, JH-H = 6.2, 1H, CHNH), 3.78 (br, $1 \mathrm{H}, \mathrm{CHNH}), 1.51$ (s, 18H, o-tBu), 1.47 (s, 9H, p- tBu), $1.72(\mathrm{~m}, 2 \mathrm{H}, \mathrm{CH} 2), 1.56(\mathrm{~m}, 2 \mathrm{H}, \mathrm{CH} 2 \mathrm{CH} 3)$, $1.22(\mathrm{~d}, \mathrm{JH}-\mathrm{H}=6.3,18 \mathrm{H}$, SiCHMe), 1.16 (sept, JH-H =6.3, 3H, SiCHMe), $0.94(\mathrm{t}, \mathrm{JH}-\mathrm{H}=7.4,3 \mathrm{H}$, 
Me). 13C\{1H\}-APT NMR plus HSQC and HMBC (100 MHz, C6D6, $298 \mathrm{~K}): \delta 141.2$ (s, Cq-Ph), 139.0 and 133.5 (both s, Cq-Ph-tBu), 121.5 (s, CPh), 110.1 (s, C1), 84.2 (s, C2), 62.3 (s, CHNH), 40.3 (s, CH2), 34.6 and 34.5 (both s, Cq-tBu), 31.8 (s, Cp-tBu), 30.3 (s, Co-tBu), 18.6 (s, $\mathrm{CH} 2 \mathrm{CH} 3$ ), 18.4 (s, SiCHMe), 13.6 (s, Me), 11.1 (s, SiCHMe). GC-MS m/z: 497 (M+, not observed), 440 (M+ - tBu), 426, 396, 382, 368, 354, 321, 285, 270, 246, 228, 207, 181.

\section{2,4,6-tri-tert-butyl-N-(1-(triisopropylsilyl)oct-1-yn-3-yl)benzenamine.}

1H NMR (400 MHz, C6D6, 298 K): $\delta 7.46$ (s, 2H, HPh), 4.33 (t, JH-H =6.6, 1H, CHNH), 3.78 (br, $1 \mathrm{H}, \mathrm{CHNH}$ ), 1.76 (td, $\mathrm{JH}-\mathrm{H}=7.1,6.6,2 \mathrm{H}, \mathrm{CH} 2$ ), 1.54, 1.34, and 1.31 (all $\mathrm{m}, 6 \mathrm{H}, \mathrm{CH} 2$ ), 1.51 (s, $18 \mathrm{H}, \mathrm{o}-\mathrm{tBu}$ ), 1.47 (s, 9H, p- tBu), 1.26 (d, JH-H =6.2, 18H, SiCHMe), 1.17 (sept, JH-H = 6.2, 3H, SiCHMe), $0.96(\mathrm{t}, \mathrm{JH}-\mathrm{H}=7.3,3 \mathrm{H}, \mathrm{Me}) .13 \mathrm{C}\{1 \mathrm{H}\}-\mathrm{APT}$ NMR plus HSQC and HMBC $(100 \mathrm{MHz}$, C6D6, 298 K): $\delta 141.1$ (s, Cq-Ph), 138.9 (s, Cq-Ph-p-tBu), 133.5 (s, Cq-Ph-o-tBu), 121.4 (s, CPh), 110.3 (s, C1), 84.2 (s, C2), 62.6 (s, CHNH), 38.0, 31.6, 25.0, and 22.8 (all s, CH2), 34.6 and 34.4 (both s, Cq-tBu), 31.7 (s, Cp-tBu), 30.3 (s, Co-tBu), 18.5 (s, SiCHMe), 13.9 (s, Me), 11.2 (s, SiCHMe). GC-MS m/z: 525 (M+, not observed), 468 (M+ - tBu), 451, 442, 421, 398, 377, 337, 321, 284, 265, 246, 223, 197, 181.

\section{2,4,6-tri-tert-butyl-N-(1-(triisopropylsilyl)undec-1-yn-3-yl)benzenamine.}

1H NMR (400 MHz, C6D6, 298 K): $\delta 7.46$ (s, 2H, HPh), 4.35 (t, JH-H = 7.3, 1H, CHNH), 3.75 (br, $1 \mathrm{H}, \mathrm{CHNH}), 1.77(\mathrm{~m}, 2 \mathrm{H}, \mathrm{CH} 2), 1.56(\mathrm{~m}, 2 \mathrm{H}, \mathrm{CH} 2), 1.50$ (s, 18H, o-tBu), 1.47 (s, 9H, p-tBu), 1.4$1.3(\mathrm{~m}, 10 \mathrm{H}, \mathrm{CH} 2), 1.22$ (d, JH-H = 6.2, 18H, SiCHMe), 1.16 (sept, JH-H = 6.2, 3H, SiCHMe), 1.01 (t, JH-H =6.4, 3H, Me). 13C $\{1 \mathrm{H}\}$-APT NMR plus HSQC and HMBC (100 MHz, C6D6, $298 \mathrm{~K}): \delta$ 141.0 (s, Cq-Ph), 139.0 and 133.4 (both s, Cq-Ph-tBu), 121.5 (s, CPh), 110.4 (s, C1), 84.3 (s, C2), 62.7 (s, CHNH), 38.1, 32.0, 31.8, 29.5, 25.3, 22.9, and 22.8 (s, CH2), 34.6 and 34.4 (both s, CqtBu), 31.8 (s, Cp-tBu), 30.2 (s, Co-tBu), 18.4 (s, SiCHMe), 14.1 (s, Me), 11.3 (s, SiCHMe). GC-MS m/z: 567 (M+, not observed), 509 (M+ - tBu), 494, 479, 463, 447, 424, 396, 370, 340, 311, 283, 265, 246, 230, 201, 185.

2,4,6-tri-tert-butyl-N-(1-(triisopropylsilyl)-4-methylpent-1-yn-3-yl)benzenamine.

1H NMR (400 MHz, C6D6, $298 \mathrm{~K}$ ): $\delta 7.47$ (s, 2H, HPh), 4.13 (d, JH-H = 5.3, 1H, CHNH), 3.78 (br, $1 \mathrm{H}, \mathrm{CHNH}$ ), 1.89 (septd, JH-H = 6.9, 5.3, 1H, CHMe), 1.51 (s, 18H, o-tBu), 1.47 (s, 9H, p-tBu), 1.25 (d, JH-H = 6.3, 18H, SiCHMe), 1.18 (sept, JH-H =6.3, 3H, SiCHMe), 1.13 and 1.06 (both d, $\mathrm{JH}-\mathrm{H}=6.9,6 \mathrm{H}, \mathrm{CHMe}) .13 \mathrm{C}\{1 \mathrm{H}\}-\mathrm{APT}$ NMR plus HSQC and HMBC (100 MHz, C6D6, $298 \mathrm{~K}): \delta$ 141.2 (s, Cq-Ph), 139.0 (s, Cq-Ph-p-tBu), 133.6 (s, Cq-Ph-o-tBu), 121.5 (s, CPh), 108.6 (s, C1), 85.2 (s, C2), 68.0 (s, CHNH), 34.6 (s, CHMe), 34.5 and 34.4 (both s, Cq-tBu), 31.8 (s, Cp-tBu), 30.2 (s, Co-tBu), 18.6 (s, SiCHMe), 18.0 and 17.2 (both s, CHMe), 11.3 (s, SiCHMe). GC-MS m/z: 497 (M+, not observed), 441 (M+ - tBu), 426, 398, 382, 365, 337, 304, 284, 261, 246, 230, 201, 181.

Computational details

All DFT theoretical calculations have been carried out using the Gaussian program package.[15] The B3LYP method[16] including the D3 dispersion correction scheme developed by Grimme[17] or both energies and gradient calculations has been employed in combination to the def2-SVP basis set[18] for all atoms. Solvent corrections were estimated by single point 
energy calculations on optimised geometries using the PCM[19] approach with benzene as solvent. The nature of the stationary points has been confirmed by analytical frequency analysis, and transition states were characterised by a single imaginary frequency corresponding to the expected motion of the atoms. Due to the well-known overestimation of the entropy in the solution calculated using the gas-phase approach, the vibrational and rotational entropy terms only are included in the free energy in solution at 353.15 K.[20] Molecular structures were represented using CYLView software.[21]

Acknowledgements

This work was supported by the Spanish Ministry of Economy and Competitiveness (MINECO/FEDER) (CONSOLIDER INGENIO CSD2009-0050, CTQ2011-27593, CTQ2012-35665 and CTQ2013-42532-P projects) and the DGA/FSE-E07. The support from KFUPM-University of Zaragoza research agreement and the Centre of Research Excellence in Petroleum Refining \& KFUPM is gratefully acknowledged. V. P. thankfully acknowledges the resources from the supercomputer "Memento", technical expertise and assistance provided by BIFI-ZCAM (Universidad de Zaragoza). L.R.-P thanks to CONACyT for a postdoctoral fellowship (204033).

Keywords: rhodium $\bullet$ propargylamines $\bullet$ hydroalkynylation $\bullet$ multicomponent reactions $\bullet$ C-H activation

[1] A. Dömling, W. Wang, K. Wang, Chem. Rev. 2012, 112, 3083-3135, and references therein.

[2] a) V. A. Peshkov, O. P. Pereshivko, E. V. van der Eycken, Chem. Soc. Rev. 2012, 41, 3790-3807; b) W.-Y. Yoo, L. Zhao, C.-J. Li, Aldrichimica Acta 2011, 44, 43-51; c) L. Zani, C. Bolm, Chem. Commun. 2006, 4263-4275.

[3] a) C. Wei, C-J. Li, J. Am. Chem. Soc. 2003, 125, 9584-9585; b) C. Wei, Z. Li, C.-J. Li, Org. Lett. 2003, 5, 4473-4475; c) P. Aschwanden, C. R. J. Stephenson, E. M. Carreira, Org. Lett. 2006, 8, 2895-2898; d) V. Kar-Yan lo, Y. Liu, M.-K. Wong, C.-M. Che, Org. Lett. 2006, 8, 15291523; e) M. Wang, P. Li, L. Wang, Eur. J. Org. Chem. 2008, 2255-2261; f) X. Zhang, A. Corma, Angew. Chem. Int. Ed. 2008, 47, 4358-4361;g) P. Li, Y. Zhang, L. Wang, Chem. Eur. J. 2009, 15, 2045-2049; h) Y. Zhang, P. Li, M. Wang, L. Wang, J. Org. Chem. 2009, 74, 4364-4367; i) W.-W. Chen, R. V. Nguyen, C.-J. Li, Tett. Lett. 2009, 50, 2895-2898; j) X. Zhou, Y. Lu, L.-L. Zhai, Y. Zhao, Q. Liu, W.-Y. Sun, RSC Adv. 2013, 3, 1732-1734; k) F. S. P. Cardoso, K. A. Abboud, A. Aponick, J. Am. Chem. Soc. 2013, 135, 14548-14551; I) M.-T. Chen, O. Navarro, Synlett 2013, 24, 11901192; m) M. Trose, M. Dell'Acqua, T. Pedrazzini, V. Pirovano, E. Gallo, E. Rossi, A. Caselli, G. Abbiati, J. Org. Chem. 2014, 79, 7311-7320.

[4] a) S. Sakaguchi, T. Kubo, Y. Ishii, Angew. Chem. Int. Ed. 2001, 40, 2534-2536; b) C.-J. Li, C. Wei, Chem. Commun, 2002, 268-269; c) S. Sakaguchi, T. Mizuta, M. Furuwan, T. Kubo, Y. Ishii, Chem . Commun., 2004, 1638-1639; d) L. Zani, S. Alesi, P. G. Cozzi, C. Bolm, J. Org. Chem. 2006, 71, 1558-1562.

[5] a) D. P. Zlotos, W. Bender, U. Holzgrabe, Exp. Opin. Ther. Patents 1999, 9, 1029-1053; b) Ringdahl, B. The Muscarinic Receptors, J. H. Brown (ed.); Humana Press Inc., Clifton NJ, 1989; c) A. A. Boulton, B. A. Davis, D. A Durden, P. H. Yu, Drug Dev. Res. 1997, 42, 150-156. 
[6] a) J. I. Gavrilyuk, U. Wuellner, C. F. Barbas III, Bioorg. Med. Chem. Lett. 2009, 19, 14211424; b) X. Li, Chem. Asian. J. 2011, 6, 2606-2616; c) A. Brik, J. Alexandratos, Y. C. Lin, J. H. Elder, A. J. Olson, A. Wlodawer, D. S. Goodsell, C. H. Wong, ChemBioChem 2005, 6, 1167-1169; d) M. Meldal, C. W. Tornøe, Chem. Rev. 2008, 108, 2952-3015; O. M. Musa, L. S. Sridhar in New Smart Materials via Metal Mediated Macromolecular Engineering, E. Khosravi, Y. Yagci, Y. Savelyev (Eds.); Springer Science + Business Media B. V. 2009, pp. 93-109.

[7] L. Rubio-Pérez, M. Iglesias, J. Munárriz, V. Polo, P. J. Sanz Miguel, J.J. Pérez-Torrente, L. A. Oro, Chem. Commun. 2015, 51, 9860-9863.

[8] a) S. P.Nolan, N-Heterocyclic Carbenes in Synthesis, Wiley-VCH, Weinheim, 2006; b) M. L. Clarke and J. J. R. Frew, in Organometallic Chemistry, ed. I. J. S. Fairlamb and J. M. Lynam, RSC Publishing, London, 2009, vol. 35, pp. 19-46; c) L. A. Adrio and K. Kuok (Mimi) Hii, in Organometallic Chemistry, ed. I. J. S. Fairlamb and J. M. Lynam, RSC Publishing, London, 2009, vol. 35, pp. 62-92; d) F. E. Hahn, M. C. Jahnke, Angew. Chem. Int. Ed., 2008, 47, 3122-3172; e) A. Poulain, M. Iglesias, M. Albrecht Curr. Org. Chem., 2011, 15, 3325-3336

[9] a) M. Albrecht, Chem. Rev. 2010, 110, 576-623; b) K. R. Jain, W. A. Herrmann, F. E. Kühn, Curr. Org. Chem. 2008, 12, 1468-1478.

[10] X. Y. Yu, H. Sun, B. O. Patrick, B. R. James, Eur. J. Inorg. Chem. 2009, 1752-1758.

[11] a) L. Rubio-Pérez, M. Iglesias, R. Castarlenas, V. Polo, J. J. Pérez-Torrente, L. A. Oro ChemCatChem 2014, 6, 3192-3199; b) X. Y. Yu, B. O. Patrick, B. R. James, Organometallics 2006, 25, 4870-4877.

[12] a) R. Azpiroz, A. Di Giuseppe, R. Castarlenas, J. J. Perez-Torrente, L. A. Oro, Chem. Eur. J. 2013, 19, 3812-3816; b) L. Rubio-Pérez, R. Azpiroz, A. Di Giuseppe, V. Polo, R. Castarlenas, J. J. Perez-Torrente, L. A. Oro, Chem. Eur. J. 2013, 19, 15304-15314; c) R. Azpíroz, A. Di Giuseppe, R. Castarlenas, J. J. Perez-Torrente, L. A. Oro, Chem. Eur. J. 2013, 19, 3812-3816; d) L. RubioPérez, R. Azpíroz, A. Di Giuseppe, V. Polo, R. Castarlenas, J. J. Pérez-Torrente, L. A. Oro, Chem. Eur. J. 2013, 19, 15304-15314; e) J. Kwak, M. Kim, S. Chang, J. Am. Chem. Soc. 2011, 133, 3780-3783; e) M. Kim, J. Kwak, S. Chang, Angew. Chem. 2009, 121, 9097-9101; Angew. Chem. Int. Ed. 2009, 48, 8935-8939.

[13] for examples see: a) P. Fristrup, M. Kreis, A. Palmelund, P.-O. Norrby, R. Madsen, J. Am. Chem. Soc. 2008, 130, 5206-5215; b) F. Abu-Hasanayn, M. E. Coldman, A. S. Goldman, J. Am. Chem. Soc. 1992, 114, 2520-2524.

[14] X.-Y. Yu, H. Sun, B. O. Patrick, B. R. James, Eur. J. Inorg. Chem. 2009, 1752-1758.

[15] Gaussian 09, Revision D.01, M. J. Frisch, G. W. Trucks, H. B. Schlegel, G. E. Scuseria, M. A. Robb, J. R. Cheeseman, G. Scalmani, V. Barone, B. Mennucci, G. A. Petersson, H. Nakatsuji, M. Caricato, X. Li, H. P. Hratchian, A. F. Izmaylov, J. Bloino, G. Zheng, J. L. Sonnenberg, M. Hada, M. Ehara, K. Toyota, R. Fukuda, J. Hasegawa, M. Ishida, T. Nakajima, Y. Honda, O. Kitao, H. Nakai, T. Vreven, J. A. Montgomery, Jr., J. E. Peralta, F. Ogliaro, M. Bearpark, J. J. Heyd, E. Brothers, K. N. Kudin, V. N. Staroverov, R. Kobayashi, J. Normand, K. Raghavachari, A. Rendell, J. C. Burant, S. S. Iyengar, J. Tomasi, M. Cossi, N. Rega, J. M. Millam, M. Klene, J. E. Knox, J. B. 
Cross, V. Bakken, C. Adamo, J. Jaramillo, R. Gomperts, R. E. Stratmann, O. Yazyev, A. J. Austin, R. Cammi, C. Pomelli, J. W. Ochterski, R. L. Martin, K. Morokuma, V. G. Zakrzewski, G. A. Voth, P. Salvador, J. J. Dannenberg, S. Dapprich, A. D. Daniels, Ö. Farkas, J. B. Foresman, J. V. Ortiz, J. Cioslowski, and D. J. Fox, Gaussian, Inc., Wallingford CT, 2009.

[16] (a) C. Lee, W. Yang, R. G. Parr, Phys. Rev. B 1988, 37, 785-789; (b) A. D. Becke, J. Chem. Phys. 1993, 98, 1372-1377; (c) A. D. Becke, J. Chem. Phys. 1993, 98, 5648-5652.

[17] S. Grimme, J. Antony, S. Ehrlich, H. Krieg, J. Chem. Phys. 2010, 132, 154104.

[18] F. Weigend, R. Ahlrichs, Phys. Chem. Chem. Phys. 2005, 7, 3297-3305.

[19] J. Tomasi, B. Mennucci, R. Cammi, Chem. Rev. 2005, 105, 2999-3093.

[20] R. Tanaka, M. Yamashita, L. W. Chung, K. Morokuma, K. Nozaki, Organometallics 2011, $30,6742-6750$.

[21] CYLView, 1.0b; C. Y. Legault, Université de Sherbrooke, 2009 (http://www.cylview.org). 